\title{
Laboratory studies of the homogeneous nucleation of iodine oxides
}

\author{
J. B. Burkholder ${ }^{1}$, J. Curtius ${ }^{1, ~}{ }^{*}$, A. R. Ravishankara ${ }^{1,}{ }^{* *}$, and E. R. Lovejoy ${ }^{1}$ \\ ${ }^{1}$ Aeronomy Laboratory, National Oceanic and Atmospheric Administration, 325 Broadway, Boulder, CO 80305-3328, USA \\ * now at: Institute for Atmospheric Physics, Mainz University, Mainz, Germany \\ ** also associated with the Dept. of Chemistry and Biochemistry, Uuniversity of Colorado, Boulder, CO 80309, USA
}

Received: 1 August 2003 - Published in Atmos. Chem. Phys. Discuss.: 7 October 2003

Revised: 5 January 2004 - Accepted: 7 January 2004 - Published: 20 January 2004

\begin{abstract}
Laboratory experimental results of iodine oxide nucleation are presented. Nucleation was induced following UV photolysis of $\mathrm{CF}_{3} \mathrm{I}$ or $\mathrm{CH}_{2} \mathrm{I}_{2}$ in the presence of excess ozone. Measurements were performed in a $70 \mathrm{~L}$ Teflon reactor with new particles detected using an Ultrafine Condensation Particle Counter, UCPC. The experimental results are interpreted using a coupled chemical - aerosol model to derive model parameters assuming single component homogeneous nucleation of OIO. The aerosol model results have been applied in an atmospheric box-model to interpret the possible implications of iodine oxide nucleation in the marine boundary layer. The model calculations demonstrate that IO and OIO concentrations reported in recent field measurements using long path absorption (Allan et al., 2000, 2001) are not sufficient to account for significant aerosol production either in the coastal or open ocean marine boundary layer using the mechanism presented. We demonstrate that inhomogeneous sources of iodine oxides, i.e. "hot" spots with elevated iodine species emissions, could account for the aerosol production bursts observed in the coastal region near Mace Head, Ireland.
\end{abstract}

\section{Introduction}

The impact of new particle formation in the troposphere on climate, both regional and global, is a topic of great interest. Sulfur chemistry probably plays an important role in new particle formation through either the $\mathrm{H}_{2} \mathrm{SO}_{4} / \mathrm{H}_{2} \mathrm{O}$ or $\mathrm{H}_{2} \mathrm{SO}_{4} / \mathrm{NH}_{3} / \mathrm{H}_{2} \mathrm{O}$ chemical systems. However, recent field studies have observed particle formation possibly related to iodine chemistry in the marine environment (O'Dowd et al., 2002 and references within) and volatile organic compounds (VOCs) in remote forested regions (Marti et al.,

Correspondence to: J. B. Burkholder

(burk@al.noaa.gov)
1997; Kavouras et al., 1998, 1999; Leaitch et al., 1999). The evaluation and impact of these sources of new particles is currently an active area of atmospheric research.

To date, the 1998-1999 PARFORCE campaign at Mace Head station on the western coast of Ireland (O'Dowd et al., 2002) is one of the most comprehensive field studies of "new" particle formation in the coastal marine environment. During this campaign, dramatic nucleation events were observed which yielded particle concentrations as high as $10^{6} \mathrm{~cm}^{-3}$ for durations of hours under certain conditions. The nucleation mechanism has not been definitively identified but the correlation with both solar flux and low tide and the identification of iodine oxides in the particles has lead to the proposal that alkyl iodides (particularly $\mathrm{CH}_{2} \mathrm{I}_{2}$ ) that are emitted by macroalgae are precursors for new particle formation (Carpenter et al., 2001 and references within).

Hoffmann et al. (2001) and Jimenez et al. (2003) have evaluated the hypothesis that alkyl iodides are responsible for the observed nucleation events through a series of laboratory experiments. In these experiments, $\mathrm{CH}_{2} \mathrm{I}_{2} / \mathrm{O}_{3} /$ Air mixtures were photolyzed in the near UV and the formation of ultra-fine particles measured. Their experiments and results from kinetic studies reported in the literature lead Hoffmann et al. (2001) to suggest the following reaction mechanism to explain new particle formation

$$
\begin{aligned}
& \mathrm{CH}_{2} \mathrm{I}_{2}+\mathrm{h} v \rightarrow \mathrm{CH}_{2} \mathrm{I}+\mathrm{I} \\
& \mathrm{I}+\mathrm{O}_{3} \rightarrow \mathrm{IO}+\mathrm{O}_{2} \\
& \mathrm{IO}+\mathrm{IO} \rightarrow \mathrm{OIO}+\mathrm{I} \\
& \mathrm{OIO}+\mathrm{OIO} \leftrightarrow \mathrm{I}_{2} \mathrm{O}_{4} \\
& \mathrm{I}_{2} \mathrm{O}_{4}+\mathrm{OIO} \leftrightarrow \leftrightarrow \leftrightarrow \text { " particle”, }
\end{aligned}
$$

where Reaction (5) represents multiple OIO addition steps leading to the formation of a stable iodine oxide cluster. In 


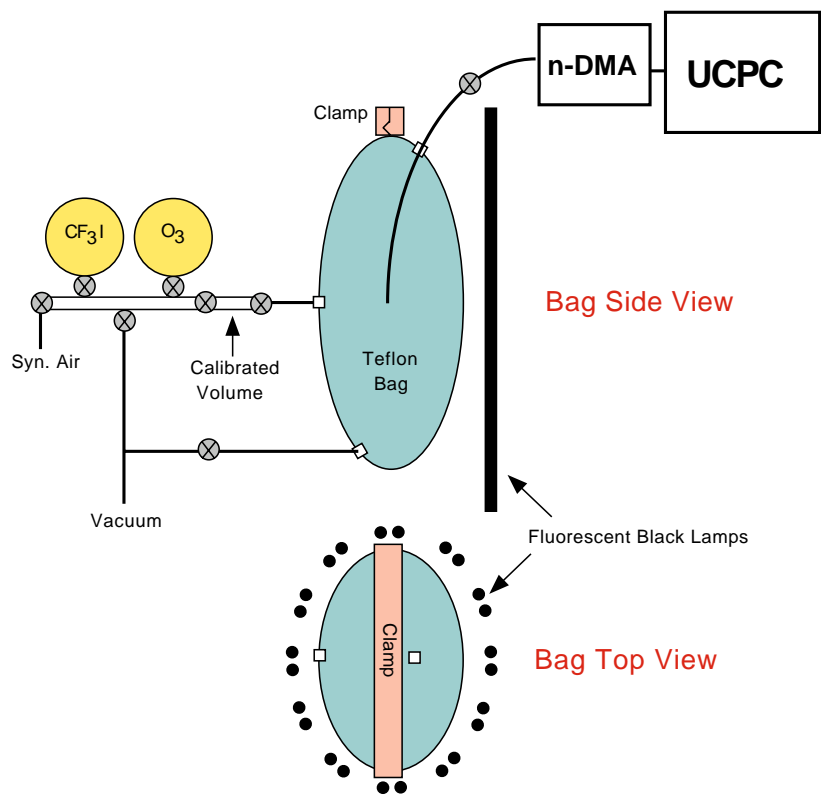

Fig. 1. Diagram of experimental apparatus. Fluorescent black lamps: BL350 or BLB365; n-DMA = nano-Differential Mobility Analyzer; UCPC $=$ Ultra-fine Condensation Particle Counter.

this mechanism, aerosol formation results from single component homogeneous nucleation of OIO. The OIO molecule has been rather elusive in the laboratory such that its physical properties are currently unknown while its reactivity and photochemical properties (Ingham et al., 2000; Ashworth et al., 2002) are topics of current study.

Although the particle formation mechanism awaits verification, Hoffmann et al. (2001) have demonstrated that UV photolysis of $\mathrm{CH}_{2} \mathrm{I}_{2}$ and $\mathrm{O}_{3}$ gas mixtures do indeed lead to iodine oxide particle formation. Jimenez et al. (2003) have subsequently extended the laboratory studies of Hoffmann et al. to include a range of $\mathrm{CH}_{2} \mathrm{I}_{2}$ concentrations nearer to that observed in the marine boundary layer (MBL). Jimenez et al. used a suite of particle analysis instrumentation to evaluate the particle composition and physical properties. The particle growth was well characterized and the particles were shown to contain mainly iodine oxides. Their work supports the particle formation mechanism proposed by Hoffmann et al. (2001).

In spite of the work of Hoffmann et al. (2001) and Jimenez et al. (2003), the ability to predict and model the iodine oxide homogeneous nucleation process in the atmosphere is still limited. A physically based parameterization of the nucleation process, which in turn can be applied, under atmospheric conditions, is needed. In this work, we have extended the laboratory measurements on the iodine oxide nucleation system through variation of critical experimental parameters to better evaluate the nucleation process. A kinetic nucleation model is presented and used to interpret the experimental observations and derive parameters that are applicable for atmospheric model calculations.

\section{Experimental details}

In this work, we have evaluated the iodine chemistry induced homogeneous nucleation by interpreting laboratory chamber measurements made under a range of controlled conditions. The conditions varied in these experiments include the initial iodine precursor concentrations, the iodine precursor molecule, photolysis rate coefficients, duration of photolysis, and temperature. For each set of experimental conditions, the time dependence of the ultra-fine particles formed was measured and interpreted using a coupled gas phase reaction mechanism and nucleation model.

Our experimental approach is similar in principle to that employed in the recent laboratory studies by Hoffmann et al. (2001) and Jimenez et al. (2003). Our work is complementary to these studies but has an emphasis on a physical (thermodynamic) description of the elementary steps in the homogeneous nucleation process. An accurate physical description of the nucleation will enable modeling homogeneous nucleation and particle formation under conditions relevant to the atmosphere.

A diagram of the experimental apparatus is given in Fig. 1. The apparatus consists primarily of the following components; (1) a Teflon bag reactor, (2) an Ultra-fine Condensation Particle Counter, UCPC, (3) a nano-differential mobility analyzer, nDMA, (4) fluorescent photolysis lamps, and (5) a gas handling manifold. The details and operation of each of these components is described separately below.

\subsection{Teflon bag reactor}

The Teflon bag reactor was made from 5 mil thick FEP Teflon $\left(24^{\prime \prime} \times 36^{\prime \prime}\right.$, flat dimensions) with welded seams on three edges. The fourth edge (along the $24^{\prime \prime}$ dimension) was sealed with a removable compression clamp to allow access to the bag interior. The bag was suspended vertically from the compression clamp and had a diameter at the center of $\sim 40 \mathrm{~cm}$ at full inflation (internal pressure 5 Torr over ambient pressure, 623 Torr). Vacuum fittings made of PFA with Viton O-ring seals were mounted near the top, center and bottom of the bag. The top fitting was used for the aerosol sampling line $\left(1 / 4^{\prime \prime}\right.$ o.d. Teflon tubing; $50 \mathrm{~cm}$ long) from the UCPC. The use of a Teflon sampling line did not influence the measurement of the uncharged iodine oxide particles. This configuration enabled the sampling line to remain stationary in the center of the bag while the bag collapsed during the course of an experiment.

The initial reactant concentrations in the bag were calculated from the measured pressures in the vacuum manifold and the volume of the bag when fully inflated (i.e. the gas phase concentrations of the compounds and reaction intermediates in the bag were not directly measured). The volume of the bag at full inflation was determined experimentally by calibrated expansions to be $72 \pm 1.5 \mathrm{~L}$. The vacuum manifold was made of Pyrex with Teflon valves. The manifold was 
used to measure and introduce the samples into the Teflon bag reactor. Pressures of the dilute reactant gas mixtures were measured with 10 and 1000 Torr capacitance manometers. A small calibrated volume, $86 \mathrm{~cm}^{3}$, was attached to the manifold and used to quantify the amount of reactant flushed into the Teflon bag reactor.

Dilute gas phase mixtures of the reactants were introduced into the bag separately through the center inlet of the bag. The experimental results were independent of the order with which the reactants were added to the bag. The gases were found experimentally to be well mixed during the filling of the bag, a procedure that took $\sim 5 \mathrm{~min}$. The reactor bag was flushed between experiments by (1) pumping out the contents until the bag collapsed onto itself, (2) fully inflating the bag with clean $\mathrm{N}_{2}$ or Air and (3) pumping out the contents again. This sequence was repeated three times. Further, background experiments with $\mathrm{O}_{3}$ and Air but no iodine precursor were then performed to confirm cleanliness, i.e. no background particle production on the time scale of our experiments, $\sim 1000 \mathrm{~s}$. The $\mathrm{O}_{3} /$ Air mixture was flushed from the bag using the steps outlined above.

The optical transmission of the Teflon bag over the wavelength range $300-400 \mathrm{~nm}$ was measured to vary smoothly from $\sim 70 \%$ to $85 \%$. The transmission of the Teflon did not change over the course of the experiments.

\subsection{Ultra-fine Condensation Particle Counter}

A commercial Ultra-fine Condensation Particle Counter, UCPC, (TSI Inc., model 3025A) ${ }^{1}$ was used to measure particle production in our experiments. The minimum size cut-off for spherical particles of the UCPC is quoted by the manufacturer to be $3 \mathrm{~nm}$ ( $50 \%$ detection efficiency). The UCPC has a maximum measurable particle density of $1 \times 10^{5}$ particle $\mathrm{cm}^{-3}$. In our experiments, particle concentration measurements were made under "high" flow, $1500 \mathrm{~cm}^{3} \mathrm{~min}^{-1}$, conditions without dilution of the sample flow while using the dynamic signal averaging algorithm of the UCPC.

The contents of the bag were sampled through $50 \mathrm{~cm}$ of $1 / 4^{\prime \prime}$ o.d. Teflon tubing that was isolated from the UCPC by a $1 / 4^{\prime \prime}$ straight bore valve at the instrument inlet. Particle loss in the sampling line was determined to be negligible, $<5 \%$, when using the "high" flow rate sampling mode of the UCPC. Particle loss was determined experimentally by comparing particle concentrations for the "high", $1500 \mathrm{~cm}^{3} \mathrm{~min}^{-1}$, and "low", $500 \mathrm{~cm}^{3} \mathrm{~min}^{-1}$, sample flows of the UCPC during an iodine nucleation experiment. The UCPC sampled the contents of the bag continuously during an experiment.

\footnotetext{
${ }^{1}$ Certain commercial equipment, instruments, or materials are identified in this article in order to adequately specify the experimental procedure. Such identification does not imply recognition or endorsement by the National Oceanic and Atmospheric Administration, nor does it imply that the material or equipment identified are necessarily the best available for the purpose.
}

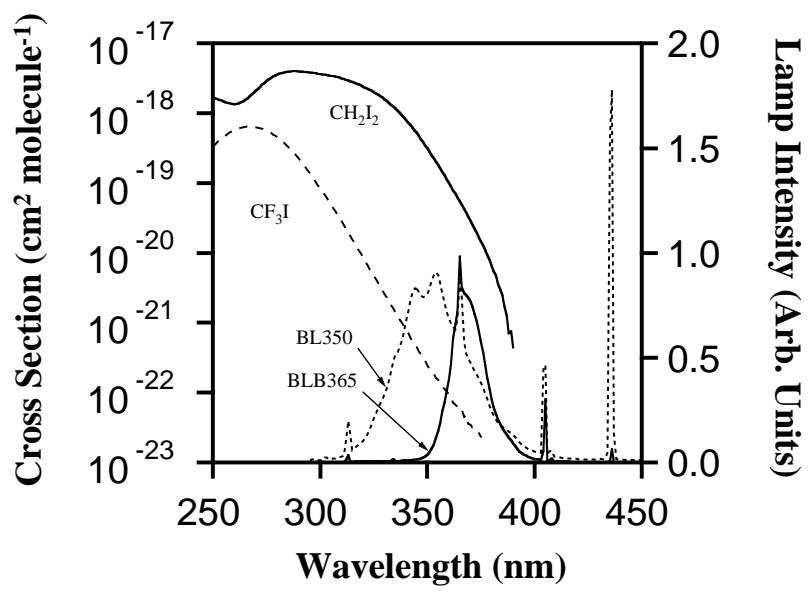

Fig. 2. Comparison of the BL350 and BLB365 photolysis lamp spectra with the absorption spectra of the $\mathrm{CF}_{3} \mathrm{I}$ and $\mathrm{CH}_{2} \mathrm{I}_{2}$ precursors used in the nucleation experiments.

In several experiments, a nano-differential mobility analyzer (nDMA, TSI Inc. Model 3085) was used to evaluate the particle size distribution. Replicate nucleation experiments were conducted under identical initial conditions while selecting 3, 5, 8, 10, and $15 \mathrm{~nm}$ diameter particles.

\subsection{Photolysis lamps}

Fluorescent black lamps were used to initiate the iodine gas phase chemistry through the photolysis of iodine containing precursor molecules $\left(\mathrm{CH}_{3} \mathrm{I}, \mathrm{CH}_{2} \mathrm{I}_{2}\right.$ or $\left.\mathrm{CF}_{3} \mathrm{I}\right)$ in the presence of excess ozone. Experiments were performed using two different types of blacklamps ( BLB365 or BL350, $40 \mathrm{~W}$ lamps, $48^{\prime \prime}$ long) with different spectral outputs. The spectral output of the lamps and the UV spectra of $\mathrm{CH}_{2} \mathrm{I}_{2}$ and $\mathrm{CF}_{3} \mathrm{I}$ are shown in Fig. 2. The BLB365 (BLB: black light blue) lamp emits between 350 and $400 \mathrm{~nm}$ with peak intensity at $365 \mathrm{~nm}$. The BLB365 lamps have weak emission at the 404 and $435 \mathrm{~nm}$ (Hg transitions) but no significant emission in the visible or UV regions. The BL350 lamp emits between 300 and $400 \mathrm{~nm}$ with peak intensity at $350 \mathrm{~nm}$. The BL350 lamps have stronger 404 and $435 \mathrm{~nm} \mathrm{Hg}$ line emission but also have no significant emission in the visible or UV regions. Twelve pairs of photolysis lamps were mounted around the perimeter of the reactor $\sim 10 \mathrm{~cm}$ from the surface of the fully inflated Teflon bag, Fig. 1. Based on the lamp geometry the light flux inside the bag was calculated to be uniform to within $\sim 20 \%$ and was brightest at the bag surface.

The average photolysis lamp flux (within the reactor bag) was experimentally determined using $\mathrm{CH}_{2} \mathrm{I}_{2}$ as an actinometer. The loss of $\mathrm{CH}_{2} \mathrm{I}_{2}$ during photolysis with the BLB365 lamps was monitored by UV absorption $(254 \mathrm{~nm})$ in an externally mounted $50 \mathrm{~cm}$ long cell. The contents of the reactor bag were continuously circulated through the absorption cell during the calibration measurement which took $\sim 30 \mathrm{~min}$. The $\mathrm{CH}_{2} \mathrm{I}_{2}$ photolysis rate coefficient (i.e. $\mathrm{CH}_{2} \mathrm{I}_{2}$ loss rate 
Table 1. Photolysis rate coefficients ${ }^{a}$

\begin{tabular}{ccc}
\hline Molecule & $\begin{array}{c}\text { BL350 Lamp } \\
\left(\mathrm{s}^{-1}\right)\end{array}$ & $\begin{array}{c}\text { BLB365 Lamp } \\
\left(\mathrm{s}^{-1}\right)\end{array}$ \\
\hline $\mathrm{CH}_{2} \mathrm{I}_{2}$ & $1.7 \times 10^{-2}$ & $\begin{array}{c}1.25 \times 10^{-3} \\
\mathrm{CF}_{3} \mathrm{I}\end{array}$ \\
& $3.3 \times 10^{-5}$ & $3.0 \times 10^{-6}$ \\
$\mathrm{O}_{3}$ & $9.5 \times 10^{-5}$ & $8.2 \times 10^{-6}$ \\
$\mathrm{IO}$ & 0.18 & 0.15 \\
$\mathrm{OIO}^{b}$ & $7.5 \times 10^{-4}$ & $7.5 \times 10^{-4}$ \\
$\mathrm{I}_{2}$ & $6.5 \times 10^{-4}$ & $1.8 \times 10^{-4}$ \\
\hline
\end{tabular}

${ }^{a}$ Reported photolysis rate coefficients are with 24 lamps in the geometry described in the text.

$b$ The photolysis rate coefficients for OIO were calculated using an absorption spectrum normalized to a cross section of $1.1 \times$ $10^{-17} \mathrm{~cm}^{2}$ molecule ${ }^{-1}$ at the peak near $540 \mathrm{~nm}$. The OIO quantum yield was assumed to be unity.

coefficient) was measured to be $(1.25 \pm 0.05) \times 10^{-3} \mathrm{~s}^{-1}$. A $\mathrm{CF}_{3} \mathrm{I}$ photolysis rate coefficient with the BL350 lamps of $3.3 \times 10^{-5} \mathrm{~s}^{-1}$ was calculated using the measured $\mathrm{CH}_{2} \mathrm{I}_{2}$ photolysis rate coefficient and the relative spectral overlap with the photolysis lamps. These BL350 lamps photolysis rate coefficients for $\mathrm{CH}_{2} \mathrm{I}_{2}$ and $\mathrm{CF}_{3} \mathrm{I}$ are approximately a factor of five greater than the values found in the atmosphere. (Roehl et al., 1995 and Solomon et al., 1994) The photolysis rate coefficients for ozone, $\mathrm{I}_{2}, \mathrm{IO}$, and $\mathrm{OIO}$ were calculated relative to the experimentally measured $\mathrm{CH}_{2} \mathrm{I}_{2}$ value and are given in Table 1 . We estimate the uncertainty in the calculated $\mathrm{CF}_{3} \mathrm{I}$ photolysis rate coefficient to be $\pm 25 \%$.

Photolytic loss of ozone is not significant in the presence of an atmosphere of air due to its rapid regeneration, $\mathrm{O}+\mathrm{O}_{2}+\mathrm{M} \rightarrow \mathrm{O}_{3}+\mathrm{M}$. The $\mathrm{I}_{2}$ photolysis rate coefficient is on the same time scale as the nucleation experiments and is therefore included in the chemical mechanism described below. The IO photolysis rate coefficient is rather high, $0.18 \mathrm{~s}^{-1}$, due to its large absorption cross section between 350 and $400 \mathrm{~nm}$. The photolysis rate coefficient of OIO is highly uncertain due to uncertainties in both its absorption cross section (Bloss et al., 2001) and quantum yields (Ingham et al., 2000; Ashworth et al., 2002). However, using reasonable values for the OIO absorption cross sections and a unit quantum yield results in a small photolysis rate coefficient with either of the BL350 or BLB365 lamps used. As will be shown in the Results and Discussion section, the photolytic loss of OIO will not significantly influence our interpretation of the nucleation experiments provided the photolysis rate coefficient of OIO is less than $0.01 \mathrm{~s}^{-1}$.

\subsection{Materials and sample handling}

Samples of $\mathrm{CH}_{2} \mathrm{I}_{2}, \mathrm{CH}_{3} \mathrm{I}, \mathrm{CF}_{3} \mathrm{I}$, and synthetic air $\left(21 \% \mathrm{O}_{2}\right.$, $79 \% \mathrm{~N}_{2}$ ) were used without purification. Upper limits for the $\mathrm{I}_{2}$ impurity in the $\mathrm{CH}_{2} \mathrm{I}_{2}, \mathrm{CH}_{3} \mathrm{I}$, and $\mathrm{CF}_{3} \mathrm{I}$ samples was determined by UV/vis absorption measurements of the pure compounds to be $<0.01 \%,<0.07 \%$, and $<0.0001 \%$, respectively. The hydrocarbon impurity in the synthetic air was determined to be less than $1 \mathrm{ppb}$ by gas chromatographic analysis. The $\mathrm{H}_{2} \mathrm{O}$ impurity of the synthetic air cylinder was quoted to be $<5 \mathrm{ppm}$.

Dilute gas mixtures of $\mathrm{CH}_{2} \mathrm{I}_{2}, \mathrm{CF}_{3} \mathrm{I}, \mathrm{CH}_{3} \mathrm{I}$ and $\mathrm{O}_{3}$ in synthetic air were prepared and stored in individual $12 \mathrm{~L}$ blackened Pyrex bulbs. The mixing ratios of these compounds in the bulbs were determined by UV absorption using either a 100 or $25 \mathrm{~cm}$ long cell and a diode array spectrometer. Periodic UV absorption measurements confirmed the sample stability, $\pm 3 \%$, over the course of the experiments.

The Teflon bag reactor was nominally operated at room temperature. A fan mounted at the base of the experimental apparatus but outside the Teflon bag, dissipated the heat generated by the photolysis lamps. Typically, the temperature of the reactor increased $\sim 2^{\circ} \mathrm{C}$ during the course of an experiment. Several nucleation experiments were also performed at elevated temperatures, $\sim 45 \pm 5^{\circ} \mathrm{C}$, by enclosing the reactor and externally heating the surrounding air with a space heater.

\section{Gas phase chemical reaction mechanism and homo- geneous nucleation model}

\subsection{Gas phase chemical reaction mechanism}

The interpretation of our experimental measurements employed a coupled gas phase chemical reaction mechanism and homogeneous nucleation model. The reaction mechanism, rate coefficients, and product yields used in the chemical mechanism are given in Table 2. The iodine precursor photolysis rate coefficients are given in Table 1. The photolysis rate coefficient was also varied in several experiments by changing the number of lamps used. There have been several rate coefficient and product yield measurements for the IO + IO reaction (Harwood et al., 1997; Bloss et al., 2001). However, despite this effort our understanding of the reaction products and their yields is still incomplete. In the present work it is assumed that OIO is the species responsible for the observed nucleation and therefore its yield in the $\mathrm{IO}+\mathrm{IO}$ reaction, 0.30 (Bloss et al., 2001) is of primary importance.

The formation and fate of the other IO + IO reaction products (I, $\mathrm{I}_{2}, \mathrm{IOI}$, and $\mathrm{I}_{2} \mathrm{O}_{2}$ ) are accounted for as follows. The yield of I atoms, Reaction (3a), is relatively small. I atoms will be rapidly converted back to IO via Reaction (2). The yield of $I_{2}$, Reaction (3b), is also relatively small, $\sim 0.05$. However, the formation of $I_{2}$ represents a small sink for 
Table 2. Gas phase reaction mechanism.

\begin{tabular}{|c|c|c|c|c|}
\hline Reaction & & $\#$ & $\begin{array}{c}\text { Rate coefficient } \\
\mathrm{cm}^{3} \text { molecule }{ }^{-1} \mathrm{~s}^{-1}\end{array}$ & Reference \\
\hline $\mathrm{CH}_{2} \mathrm{I}_{2}+\mathrm{h} v$ & $\rightarrow$ Products + I & 1 & See Table 1 & \\
\hline $\mathrm{CF}_{3} \mathrm{I}+\mathrm{h} v$ & $\rightarrow$ Products + I & 1 & See Table 1 & \\
\hline $\mathrm{I}+\mathrm{O}_{3}$ & $\rightarrow \mathrm{IO}+\mathrm{O}_{2}$ & 2 & $1.2 \times 10^{-12}$ & Turnipseed et al. (1995) \\
\hline $\mathrm{IO}+\mathrm{IO}$ & $\begin{array}{l}\rightarrow \text { Products } \\
\rightarrow 2 \mathrm{I}+\mathrm{O}_{2} \\
\rightarrow \mathrm{I}_{2}+\mathrm{O}_{2} \\
\rightarrow \mathrm{OIO}+\mathrm{I} \\
\rightarrow \mathrm{IOI}+\mathrm{O} \\
\rightarrow \mathrm{I}_{2} \mathrm{O}_{2}\end{array}$ & $\begin{array}{c}3(a-e) \\
3(a) \\
3(b) \\
3(c) \\
3(d) \\
3(e)\end{array}$ & $\begin{array}{l}1 \times 10^{-10} \\
\Phi=0.05 \\
\Phi=0.30\end{array}$ & Harwood et al. (1997) \\
\hline $\mathrm{IO}+\mathrm{O}_{3}$ & $\rightarrow \mathrm{OIO}+\mathrm{O}_{2}$ & 18 & $\sim 5 \times 10^{-15}$ & This work \\
\hline
\end{tabular}

reactive iodine because of the relatively slow $\mathrm{I}_{2}$ photolysis in our apparatus. IOI has not been identified as a reaction product in the IO self-reaction and is assumed to be zero in our analysis. It is assumed that the $\mathrm{IO}$ dimer, $\mathrm{I}_{2} \mathrm{O}_{2}$, represents the balance of the reaction products. The chemical properties of $\mathrm{I}_{2} \mathrm{O}_{2}$ are currently unknown but by analogy with the chlorine and bromine dimers, $\mathrm{Cl}_{2} \mathrm{O}_{2}$ and $\mathrm{Br}_{2} \mathrm{O}_{2}$, it is expected to be thermally unstable at room temperature (Sander et al., 2002). $\mathrm{I}_{2} \mathrm{O}_{2}$ is therefore expected to rapidly decompose back to IO radicals at room temperature and represent a null cycle with respect to the $\mathrm{IO}$ radical concentration.

Reaction (1), the photolysis of $\mathrm{CH}_{2} \mathrm{I}_{2}$, produces $\mathrm{I}$ and $\mathrm{CH}_{2} \mathrm{I}$ radicals as products. The $\mathrm{CH}_{2} \mathrm{I}$ radical can release the second iodine atom via the following sequence of reactions.

$\mathrm{CH}_{2} \mathrm{I}+\mathrm{O}_{2} \rightarrow \mathrm{CH}_{2} \mathrm{IOO}$

$\mathrm{CH}_{2} \mathrm{IOO}+\mathrm{CH}_{2} \mathrm{IOO} \rightarrow 2 \mathrm{CH}_{2} \mathrm{IO}+\mathrm{O}_{2}$

$\mathrm{CH}_{2} \mathrm{IO} \rightarrow \mathrm{CH}_{2} \mathrm{O}+\mathrm{I}$.

Both Reactions (6) and (8) are expected to be rapid and for our purposes are instantaneous while Reaction (7) is rate limiting. The rate coefficient for Reaction (7) has not been reported. The chemical model used in the analysis of the $\mathrm{CH}_{2} \mathrm{I}_{2}$ experiments does not treat the $\mathrm{CH}_{2} \mathrm{I}$ radical explicitly but assumes an immediate release of the I atom.

Although previous laboratory measurements (Hoffmann et al., 2001; Jimenez et al. 2003) have exclusively used $\mathrm{CH}_{2} \mathrm{I}_{2}$ as the iodine precursor, we have used $\mathrm{CF}_{3} \mathrm{I}$ as the I atom precursor for the bulk of the measurements for the reasons outlined below. First, $\mathrm{CF}_{3} \mathrm{I}$ contains a single I atom which is released upon photolysis and therefore represents a "cleaner" and better characterized I atom source than $\mathrm{CH}_{2} \mathrm{I}_{2}$. Second, due to the significant differences in photolysis rate coefficients (Table 1), $\mathrm{CF}_{3} \mathrm{I}$ yields a nearly constant iodine atom production rate over the duration of the measurements, $\sim 1000 \mathrm{~s}$, while $\mathrm{CH}_{2} \mathrm{I}_{2}$ is significantly depleted over this time period. The $\mathrm{CF}_{3} \mathrm{I}$ purity is sufficiently high, i.e. low $\mathrm{I}_{2} \mathrm{im}-$ purity, that background aerosol production was not observed when high concentrations of $\mathrm{CF}_{3} \mathrm{I}$ were used. $\mathrm{CF}_{3} \mathrm{I}$ therefore represents a well characterized I atom source. Finally, the high vapor pressure of $\mathrm{CF}_{3} \mathrm{I},>1 \mathrm{~atm}$., makes handling the samples and flushing the Teflon bag more efficient than for $\mathrm{CH}_{2} \mathrm{I}_{2}, \sim 2$ Torr vapor pressure.

\subsection{Homogeneous nucleation model}

The aerosol model combines a full kinetic treatment of the nucleation steps of the OIO clusters with a "sectional" aerosol model (Raes and Janssens, 1985) to treat the growth and coagulation of the larger nucleated particles. The nucleation portion of the model consists of 20-50 bins that increment by a single OIO molecule starting with the OIO monomer. The nucleation portion of the model is coupled to a second set of bins in which the number of OIO molecules in a bin are incremented geometrically, typically by a factor of 1.5. There are usually about 40 bins for the large clusters, giving a maximum particle diameter of about $1 \mu \mathrm{m}$.

The evolution of OIO is described by the following differential equation,

$$
\frac{\partial[\mathrm{OIO}]}{\partial t}=P-\sum_{i} k_{i}^{a}[\mathrm{OIO}][i]+\sum_{i} k_{i}^{d}[i],
$$

where $P$ is the OIO production rate from the gas phase chemistry, $k_{i}^{a}$ is the average second order rate coefficient for addition of OIO to a cluster $i$ with concentration $[i], k_{i}^{d}$ is the average first order rate coefficient for evaporation of OIO from cluster $i$. OIO is produced in a series of gas phase reactions involving I atoms and ozone, that are described in the chemical mechanism section. The first sum on the right hand side 


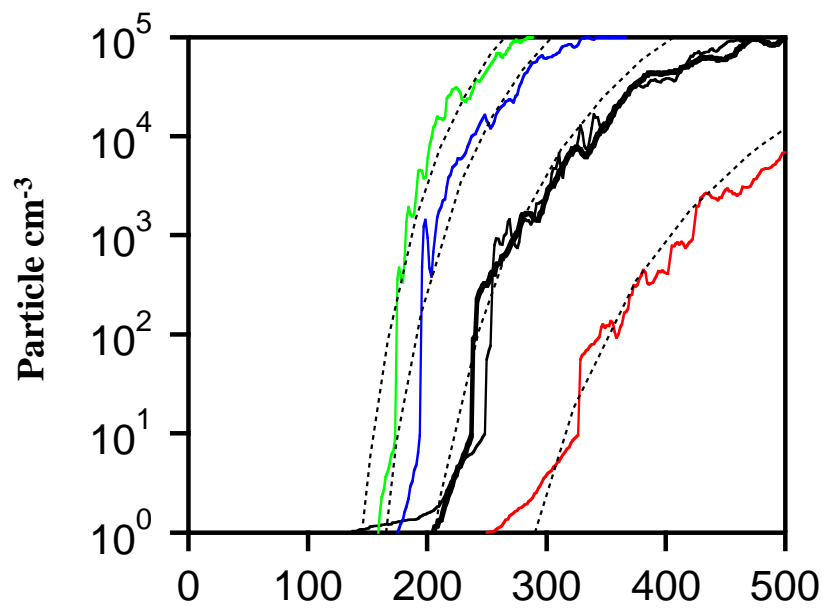

Time (s)

Fig. 3. Dependence of particle production on the initial $\mathrm{CF}_{3} \mathrm{I}$ concentration with a fixed ozone concentration, $30 \mathrm{ppb}$, and BL350 photolysis lamps (24 total). The $\mathrm{CF}_{3} \mathrm{I}$ concentrations were: 5.50 (red), 10.5 (black), 16.1 (blue), 20.8 (green) ppb (solid lines, right to left). BL350 photolysis lamps (24 total) were used. The scaling of the particle production with the photolysis flux and initial $\mathrm{CF}_{3} \mathrm{I}$ concentration is illustrated for half the photolysis flux (12 lamps) and $21.0 \mathrm{ppb} \mathrm{CF}_{3} \mathrm{I}$ (heavy black line). The aerosol model simulations are shown as dashed line (see text for details).

of Eq. (9) accounts for the condensation of OIO, and the second sum is the rate of OIO production by cluster evaporation.

The differential equation describing the evolution of OIO cluster $i$ is (see e.g. Raes and Janssens, 1985, 1986):

$$
\begin{aligned}
& \frac{\partial[i]}{\partial t}=\frac{k_{i+1}^{d}}{n_{i+1}-n_{i}}[i+1] \frac{k_{i}^{d}}{n_{i}-n_{i-1}}[i] \\
& +\frac{k_{i-1}^{a}[\mathrm{OIO}][i-1]}{n_{i}-n_{i-1}}-\frac{k_{i}^{a}[\mathrm{OIO}][i]}{n_{i+1}-n_{i}} \\
& +\sum_{l} \sum_{j} k_{j, l}^{c}[j][l] \frac{\left(\left(n_{l}+n_{j}\right)-n_{i-1}\right)}{\left(n_{i}-n_{i-1}\right)} \delta_{\left.\left.n_{l}+n_{j},\right] n_{i-1}, n_{i}\right]} \\
& +\sum_{l} \sum_{j} k_{j, l}^{c}[j][l] \frac{\left(n_{i+1}-\left(n_{l}+n_{j}\right)\right)}{\left(n_{i+1}-n_{i}\right)} \delta_{\left.\left.n_{l}+n_{j},\right] n_{i}, n_{i+1}\right]} \\
& -\sum_{j} k_{i, j}^{c}[i][j]+\text { Wall Loss, }
\end{aligned}
$$

where $[i]$ is the concentration of the cluster in bin $i$ containing $n_{i}$ OIO molecules, and $k_{j, l}^{c}$ is the average second order rate coefficient for coagulation of a cluster with $n_{j}$ OIO molecules and a cluster with $n_{l}$ OIO molecules. The delta function is defined by

$\delta_{\left.\left.n_{l}+n_{j},\right] n_{i-1}, n_{i}\right]}=\begin{aligned} & \left.\left.0 \text { if } n_{l}+n_{j} \notin\right] n_{i-1}, n_{i}\right] \\ & \left.\left.1 \text { if } n_{l}+n_{j} \in\right] n_{i-1}, n_{i}\right] .\end{aligned}$

The first term on the righthand side of Eq. (10) describes the production of cluster $i$ by the loss of OIO from the next larger cluster $(i+1)$. The second term accounts for the loss of $i$ due to evaporation of OIO. The third term is the production of $i$ by addition of OIO to the next smaller cluster, and the fourth term is the loss of $i$ by reaction with OIO. The fifth and sixth terms describe the production of $i$ by coagulation of smaller clusters. The last term is the loss of cluster $i$ by coagulation with all other clusters.

Coagulation coefficients are calculated by using Dahneke's (Seinfeld and Pandis, 1998, Sects. 8 and 12) form for the Brownian coagulation coefficient.

$k_{12}=\frac{2 \pi\left(D_{p 1}+D_{p 2}\right)\left(D_{1}+D_{2}\right)(1+K n)}{1+2 K n(1+K n) / \alpha}$,

where $D_{p i}$ is the diameter of particle $i, D_{i}$ is the diffusion coefficient of particle $i, K n$ is the Knudsen number, and $\alpha$ is the accommodation coefficient. Geometric radii were calculated assuming spherical clusters with variable density. The Knudsen number is given by

$K n=\frac{4\left(D_{1}+D_{2}\right)}{\overline{c_{12}}\left(D_{p 1}+D_{p 2}\right)}$,

where $\overline{c_{12}}=\sqrt{c_{1}^{2}+c_{2}^{2}}$ and $c_{i}$ is the mean molecular speed of particle $i$. The diffusion constant is

$D_{i}=\frac{k T C_{c i}}{3 \pi \mu D_{p i}}$,

where $C_{c i}$ is the slip correction (Seinfeld and Pandis, 1998) and $\mu$ is the viscosity of air. OIO condensation rate coefficients were calculated with Dahneke's formula for condensation, which is the same as the coagulation Eq. (12) in the small cluster limit. The set of differential equations describing cluster growth, evaporation, and coagulation was integrated by using a semi-implicit extrapolation method suitable for stiff sets of equations (Press et al., 1992).

For the simple case of homogeneous nucleation of gas phase species OIO, the individual growth/evaporation steps are given by

$$
(\mathrm{OIO})_{\mathrm{n}}+\mathrm{OIO} \leftrightarrow(\mathrm{OIO})_{\mathrm{n}+1} \quad k_{n}^{a}, k_{n+1}^{d}
$$

The growth and evaporation rate constants are related to the standard Gibbs free energy change for the reaction $\left(\Delta G_{n, n+1}^{0}\right)$,

$K_{p}=\exp \left(\frac{-\Delta G_{n, n+1}^{0}}{R T}\right)=\frac{1}{R T} \frac{k_{n}^{a}}{k_{n+1}^{d}}$,

where $K_{p}$ is the equilibrium constant with units of $1 / p$ ( $p=$ standard state pressure), $R$ is the gas constant and $T$ is the temperature.

OIO cluster evaporation rate constants were calculated by using Dahnekes condensation rate constants and parameterized thermodynamics for the clusters. It was assumed that 
Table 3. Aerosol model parameter definitions and optimized values.

\begin{tabular}{ccc}
\hline Parameter & Definition & Value \\
\hline Variable & & \\
$\Delta \mathrm{H}_{\mathrm{c}}$ & Enthalpy of OIO Condensation & $-35 \mathrm{kcal} \mathrm{mol}^{-1}$ \\
$\Delta \mathrm{H}_{\text {Dimer }}^{0}$ & Bond Enthalpy of OIO Dimer & $-17 \mathrm{kcal} \mathrm{mol}^{-1}$ \\
$a$ & Transition: Dimer to Bulk & 4 \\
$\rho$ & Density of OIO cluster & $2.5 \mathrm{~g} \mathrm{~cm}^{-3}$ \\
$\gamma$ & OIO Uptake Coefficient & 1.0 \\
Fixed & & \\
$r$ & UCPC: Particle radius detection limit & $1.5 \mathrm{~nm}$ \\
\hline
\end{tabular}

the OIO binding enthalpy varied as a function of the number of OIO units in the cluster as follows

$\Delta \mathrm{H}_{n, n+1}^{0}=\Delta \mathrm{H}^{0}{ }_{c}-\left(\Delta \mathrm{H}^{0}{ }_{c}-\Delta \mathrm{H}_{\text {Dimer }}^{0}\right) e^{-(n-1) / a}$,

where $\Delta \mathrm{H}_{c}$ is the enthalpy of condensation for the bulk $(n \rightarrow \infty), \Delta \mathrm{H}_{\text {Dimer }}^{0}$ is the enthalpy for the OIO dimer, and $a$ adjusts the rate of exponential variation of the enthalpy from the dimer to the bulk. The entropy change for adding OIO to all clusters was assumed to be $-0.03 \mathrm{kcal} \mathrm{mol}^{-1} \mathrm{~K}^{-1}$ and the Gibbs free energies were calculated as $\Delta \mathrm{G}=\Delta \mathrm{H}-\mathrm{T} \Delta \mathrm{S}$. This gives a convenient method to vary the height and position of the nucleation barrier and a "semi-physical" representation of the variation of the monomer binding energy with cluster size.

\section{Results and discussion}

During the course of our studies, we considered three different photolytic sources of iodine atoms $\left(\mathrm{CF}_{3} \mathrm{I}, \mathrm{CH}_{3} \mathrm{I}\right.$, and $\mathrm{CH}_{2} \mathrm{I}_{2}$ ) to initiate particle production. $\mathrm{CH}_{3} \mathrm{I}$ was used in just a few preliminary measurements and found unsuitable as an iodine precursor for the reasons outlined below. First, the poor spectral overlap of the photolysis lamp output and the $\mathrm{CH}_{3} \mathrm{I}$ absorption spectrum necessitated using relatively high initial concentrations of $\mathrm{CH}_{3} \mathrm{I}(\sim 400 \mathrm{ppb})$ to achieve the desired iodine radical production rate. When using these high concentrations, we observed significant background particle production (i.e. prior to photolysis) that was initiated by the room lights. This most likely implies that $\mathrm{I}_{2}\left(\mathrm{a} \mathrm{CH}_{3} \mathrm{I}\right.$ impurity that photolyzes at visible wavelengths) may be responsible for the initiation of the iodine chemistry and subsequent particle production. $\mathrm{I}_{2}$ photolysis would be a significant I atom source in the nucleation experiments, even though the BLB365 photolysis lamps do not emit strongly in the visible region, relative to that from $\mathrm{CH}_{3} \mathrm{I}$. The uncertainties in the iodine atom production rate associated with the $\mathrm{I}_{2}$ impurity make $\mathrm{CH}_{3} \mathrm{I}$ an unsatisfactory iodine precursor. Nucleation experiments were performed with both $\mathrm{CH}_{2} \mathrm{I}_{2}$ and $\mathrm{CF}_{3} \mathrm{I}$ used as the iodine precursor. As discussed in the Experimental section, there are a number of advantages in using $\mathrm{CF}_{3} \mathrm{I}$ as the iodine precursor. Although we have performed numerous measurements using $\mathrm{CH}_{2} \mathrm{I}_{2}$ as the iodine precursor, this data set was not used in the determination of the aerosol model parameters. However, because $\mathrm{CH}_{2} \mathrm{I}_{2}$ was used exclusively in the Hoffmann et al. (2001) and Jimenez et al. (2003) studies, some representative $\mathrm{CH}_{2} \mathrm{I}_{2}$ data, modeling, and discussion of our data are presented at the end of this section for comparison purposes.

The nucleation experimental data consists of the particle concentration as a function of time following the initiation of photolysis. In this section, we will first present some representative experimental data recorded using both continuous and pulsed photolysis. This is followed by a quantitative analysis of the data using the coupled chemical and aerosol model. For convenience of discussion, we define a parameter, $\tau$, as the induction time between the initiation of photolysis and the initial detection of particles. Smaller values of $\tau$ indicate more efficient particle production. Other parameters that are useful in describing the efficiency of particle production are the rate of increase in particle concentration and the final particle concentration. In many cases, the final particle concentration exceeded the upper limit of the UCPC making this diagnostic parameter of limited value. In general, the particle production temporal profiles showed good reproducibility under all the experimental variations. For example, $\tau$ was reproducible to within $\sim 10 \mathrm{~s}$ while the final particle concentration was typically reproducible to within $\sim 50 \%$.

Examples of particle production with continuous photolysis for initial $\mathrm{CF}_{3} \mathrm{I}$ concentrations between 5.00 and $21.0 \mathrm{ppb}$ and $\left[\mathrm{O}_{3}\right]=30 \mathrm{ppb}$ are shown in Fig. 3. In these experiments $\tau$ varied from 300 to $160 \mathrm{~s}$ with the shortest times observed with the highest $\mathrm{CF}_{3} \mathrm{I}$ concentration, i.e. highest radical concentrations. The particle concentration shows a rapid rise in all cases with the rate dependent on the $\mathrm{CF}_{3} \mathrm{I}$ concentration, i.e. faster rate of rise at higher concentration. Finally, the final particle concentration observed over the first $500 \mathrm{~s}$ of the experiment exceeds $10^{5}$ particle $\mathrm{cm}^{-3}$ for the highest $\mathrm{CF}_{3} \mathrm{I}$ concentrations but shows a systematic decrease with decreasing $\mathrm{CF}_{3} \mathrm{I}$ concentration for the lower values. These characteristics of the temporal profiles are evaluated quantitatively using the aerosol model.

The particle production dependence on the photolysis rate coefficient is also shown in Fig. 3. Measurements were made using the highest $\mathrm{CF}_{3} \mathrm{I}$ concentration, $21.0 \mathrm{ppb}$, and half the photolysis lamps, i.e. half the iodine atom production rate. The particle production is nearly coincident with the particle profile recorded using full photolysis and $10.5 \mathrm{ppb} \mathrm{CF}_{3} \mathrm{I}$. This measurement along with others which are not shown using $1 / 2$ and $1 / 4$ of the photolysis lamps demonstrate that the particle production linearly scales with the iodine atom production rate, i.e. photolysis flux $\times\left[\mathrm{CF}_{3} \mathrm{I}\right]$. This is the expected dependence of the coupled chemical mechanism and aerosol model. The scaling with variations in photolysis flux 


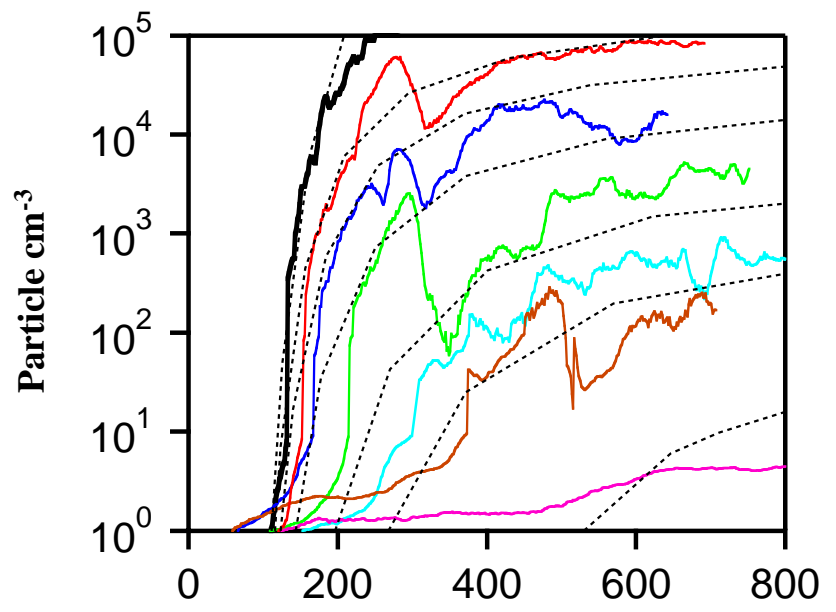

Time (s)

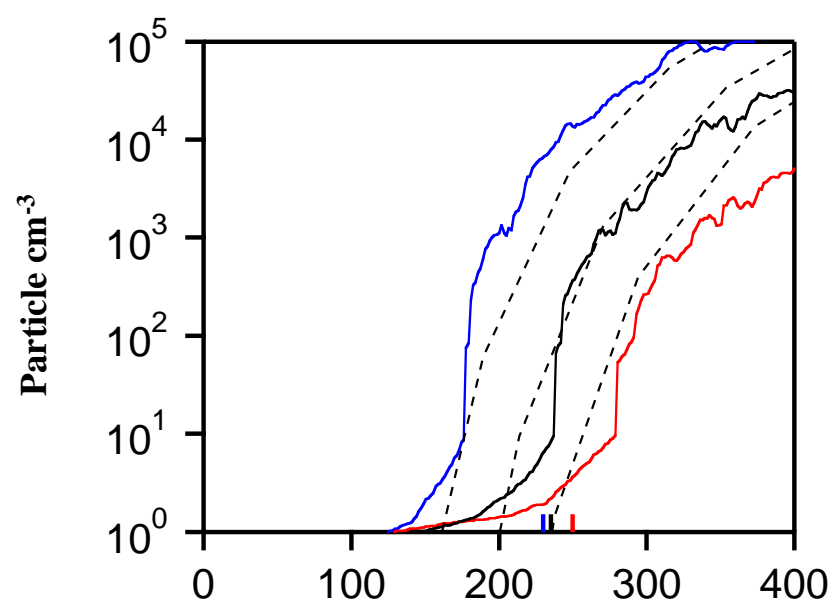

Time (s)
Fig. 4. Particle production following $13 \mathrm{~s}$ (purple), $22 \mathrm{~s}$ (brown), $30 \mathrm{~s}$ (light blue), $45 \mathrm{~s}$ (green), $60 \mathrm{~s}$ (blue), and $75 \mathrm{~s}$ (red) pulses of photolysis with $21.0 \mathrm{ppb} \mathrm{CF}_{3} \mathrm{I}$ and $500 \mathrm{ppb} \mathrm{O}_{3}$. The particle profile obtained with continuous photolysis is shown as the heavy black line. The aerosol model simulations are shown as dashed lines.

and initial $\mathrm{CF}_{3} \mathrm{I}$ concentration also demonstrates that the photolysis flux within the reactor is reasonably uniform in terms of particle production.

For the experimental data shown in Fig. 3, the IO radical concentration rapidly rises over the first $100 \mathrm{~s}$ to a nearly steady-state value. The IO steady-state concentrations calculated using the chemical mechanism given in Table 2 for initial $\mathrm{CF}_{3} \mathrm{I}$ concentrations of 5.50, 10.5, 16.1, $20.8 \mathrm{ppb}$ are $10.8,15.4,19.5$, and $22.3 \mathrm{ppt}$, respectively. The OIO radical concentration increases throughout the measurement time to values of 50, 95, 102, and $104 \mathrm{ppt}$ at $500 \mathrm{~s}$. We should note that while the concentrations of the IO and OIO radicals in these experiments are appropriate for the evaluation of iodine oxide nucleation in the laboratory experiments they greatly exceed the concentrations measured in the atmosphere (Allan et al., 2000, 2001).

The pulsed photolysis method was used as a means to achieve lower iodine radical concentrations. An example of particle production measured using the photolysis pulse method is shown in Fig. 4. Measurements were made using $13,22,30,45,60$, and $75 \mathrm{~s}$ of photolysis with $21.0 \mathrm{ppb}$ of $\mathrm{CF}_{3} \mathrm{I}$ and $500 \mathrm{ppb}$ of $\mathrm{O}_{3}$. This combination yields total reactive iodine concentrations of $9,16,21,32,43$, and $54 \mathrm{ppt}$ for the increasing durations of photolysis. As shown in Fig. 4, particle production was observed in each case although the yield was small for the $13 \mathrm{~s}$ photolysis measurement. The data also clearly shows a very strong non-linear dependence on the initial I atom concentration while $\tau$ varied from 600 to $150 \mathrm{~s}$. For example, the final particle concentration increased nearly three orders of magnitude for a factor of three increase in the initial I atom concentration. This highly non-linear de-
Fig. 5. Ozone dependence of the iodine oxide particle formation. Ozone concentrations are 20 (red), 98 (black), and 486 (blue) $\mathrm{ppb}$ with a fixed initial $\mathrm{CF}_{3} \mathrm{I}$ concentration of $9.80 \mathrm{ppb}$. Aerosol model calculations (dashed lines) were made with $k_{18}\left(\mathrm{IO}+\mathrm{O}_{3} \rightarrow \mathrm{OIO}+\mathrm{O}_{2}=5 \times 10^{-15} \mathrm{~cm}^{3}\right.$ molecule ${ }^{-1} \mathrm{~s}^{-1}$. The vertical lines on the time axis indicate the aerosol model calculated values of $\tau$ without the $\mathrm{IO}+\mathrm{O}_{3}$ reaction included in the model (lowest ozone concentration on the right).

pendence is characteristic for homogeneous nucleation with a free energy barrier. The particle profiles shown in Fig. 4 have some significant variations in concentration that were normally not observed in the continuous photolysis experiments. These variations may represent inhomogeneities in the particle distribution within the bag. Also shown in Fig. 4, for comparison, is the particle production measured with the same $\mathrm{CF}_{3} \mathrm{I}$ and $\mathrm{O}_{3}$ concentrations and continuous photolysis, $\tau=140 \mathrm{~s}$ and $10^{5}$ particle $\mathrm{cm}^{-3}$ at $210 \mathrm{~s}$.

The particle formation was a function of the initial ozone concentration (with a fixed initial $\mathrm{CF}_{3} \mathrm{I}$ or $\mathrm{CH}_{2} \mathrm{I}_{2}$ concentration and photolysis flux). An ozone dependence of the particle production was not reported in the Hoffmann et al. (2001) and Jimenez et al. (2003) studies. Particle production profiles, using continuous photolysis, with $\left[\mathrm{CF}_{3} \mathrm{I}\right]=9.80 \mathrm{ppb}$ and ozone concentrations of 20,98 , and $486 \mathrm{ppb}$ are shown in Fig. 5 to illustrate the $\mathrm{O}_{3}$ dependence. In the modeling and data analysis described below, we have attributed the ozone dependence to the gas phase reaction

$$
\mathrm{IO}+\mathrm{O}_{3} \rightarrow \mathrm{OIO}+\mathrm{O}_{2}\left(\Delta \mathrm{H}_{\mathrm{r}}=-44 \mathrm{kcal} \mathrm{mol}^{-1}\right) .
$$

This source of OIO is pseudo-first order in IO under our experimental conditions and becomes most significant at low IO and high ozone concentrations. A global data analysis of the particle production data yielded a rate coefficient of $\sim 5 \times 10^{-15} \mathrm{~cm}^{3}$ molecule ${ }^{-1} \mathrm{~s}^{-1}$ for Reaction (18).

An upper limit for Reaction (18) has been reported, $<2 \times 10^{-16} \mathrm{~cm}^{3}$ molecule $\mathrm{s}^{-1}$ (see Atkinson et al., 2003) 
which is in slight conflict with the value presented here. Rate coefficients for the analogous $\mathrm{ClO}$ and $\mathrm{BrO}$ reactions with $\mathrm{O}_{3}$ have been reported, $<1 \times 10^{-18} \mathrm{~cm}^{3}$ molecule $\mathrm{e}^{-1} \mathrm{~s}^{-1}$ and $\sim 2 \times 10^{-18} \mathrm{~cm}^{3}$ molecule ${ }^{-1} \mathrm{~s}^{-1}$, respectively (Sander et al., 2002), and are also relatively slow. Direct kinetic studies of Reaction (18) would greatly aid the correct assignment of the observed nucleation dependence on ozone concentration. It should be noted, however, that the conclusions drawn from the model analysis of the particle production data are only very weakly dependent on this rate coefficient and/or its assignment in the chemical mechanism. The possible importance of Reaction (18) as an OIO source in the marine boundary layer is discussed in the Atmospheric Implications section.

\subsection{Aerosol model simulations}

The coupled chemical and aerosol model was used to simulate the $\mathrm{CF}_{3} \mathrm{I}$ experimental data and determine the thermodynamic parameters, Eq. (17), that best describe the iodine oxide nucleation using the mechanism given in Table 2. The aerosol model parameters, their definitions, and their optimized values are summarized in Table 3. The optimized model simulations are shown in each of the data figures and reproduce the experimental data very well under all experimental conditions.

Although each of the model parameters are uniquely defined in the aerosol model there does exist some correlation of the model parameters in the data analysis. A sensitivity analysis for the $\Delta \mathrm{H}_{c}, \Delta \mathrm{H}_{\text {Dimer, }}^{0}$, and a parameters was performed to evaluate the uncertainties in the individual parameters. In this analysis, the parameters were varied individually over a range of reasonable values while comparing the calculated particle production profiles to the experimentally measured values. From these calculations, we found that particle production was not possible for $\Delta \mathrm{H}_{c}>-25 \mathrm{kcal} \mathrm{mol}^{-1}$. Second, provided the value of $\Delta \mathrm{H}_{c}$ is below this upper limit the model results are somewhat insensitive to its value within the range -30 to $-70 \mathrm{kcal} \mathrm{mol}^{-1}$. We have taken a value of $-35 \mathrm{kcal} \mathrm{mol}^{-1}$ as a reasonable estimate.

The "a" parameter was varied between 2 and 7 in the sensitivity analysis. The calculations were not overly sensitive to the value of $a$. Reasonable fits to the experimental data were obtained with values between 3 and 5 . We have taken $a=4$ for the final analysis.

The modeled particle production is most sensitive to the bond enthalpy of the OIO dimer, $\Delta \mathrm{H}_{\text {Dimer }}^{0}$. In our calculations, $\Delta \mathrm{H}_{\text {Dimer }}^{0}$ was varied between -14 and $-22 \mathrm{kcal} \mathrm{mol}^{-1}$ with the optimum value being $-17 \mathrm{kcal} \mathrm{mol}^{-1}$. A range of $\pm 2 \mathrm{kcal} \mathrm{mol}^{-1}$ in $\Delta \mathrm{H}_{\text {Dimer }}^{0}$ was estimated based on the range of reasonable values for the a and $\Delta \mathrm{H}_{c}$ parameters. This value of $\Delta \mathrm{H}_{\text {Dimer }}^{0}$ corresponds to a moderately bound OIO dimer with a bond strength of $\sim 17 \mathrm{kcal} \mathrm{mol}^{-1}$. To date there are no thermodynamic parameters for the OIO dimer available in the literature with which to compare this value.
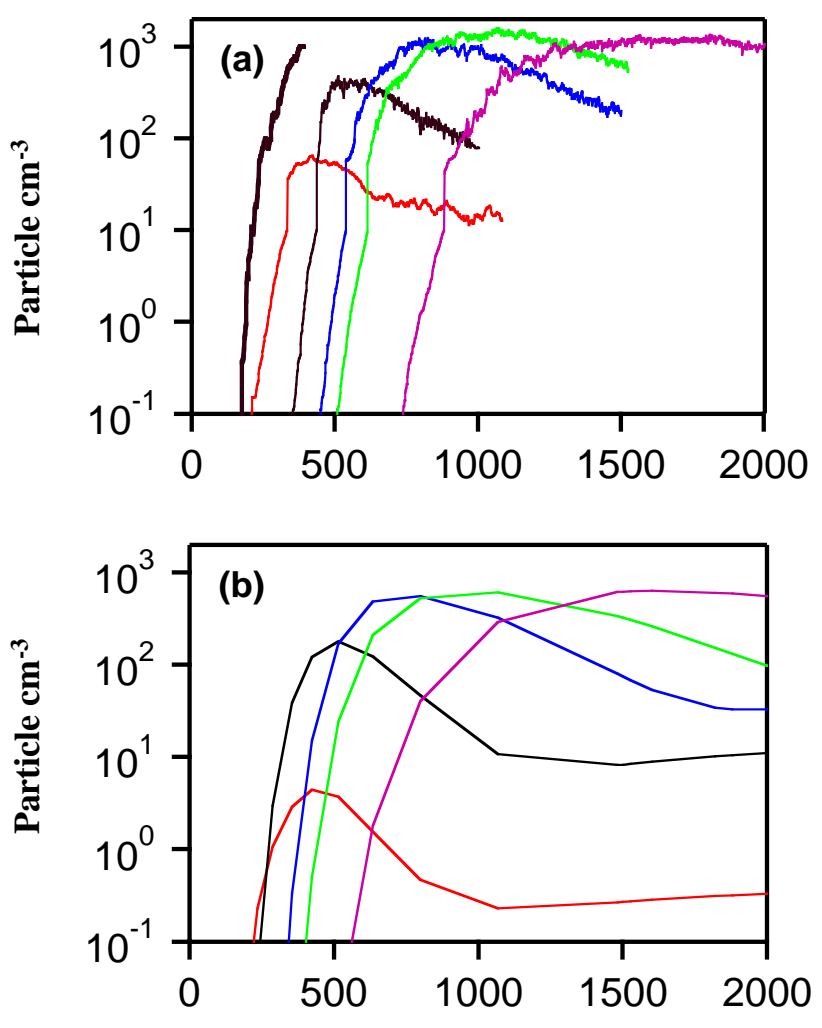

Time (s)

Fig. 6. Particle concentration profiles measured using the n-DMA with BL350 photolysis lamps (24) and $21.0 \mathrm{ppb} \mathrm{CF}_{3} \mathrm{I}$ and $30 \mathrm{ppb}$ $\mathrm{O}_{3}$. (a) Measured concentrations: $3 \mathrm{~nm}$ (red), $5 \mathrm{~nm}$ (black), $8 \mathrm{~nm}$ (blue), $10 \mathrm{~nm}$ (green), and $15 \mathrm{~nm}$ (purple) diameter particles. The measured total particle concentration ( $>3 \mathrm{~nm}$ dia.) under these conditions divided by 100 is given at the far left. (b) The corresponding particle size profiles calculated using the aerosol model and parameters determined in this work.

The iodine oxide particle density and uptake coefficient for small particles, $<20 \mathrm{~nm}$ diameter, are currently not known and therefore were treated as variable parameters in the model simulations. Model calculations (which assumes spherical particles) were performed using densities of 1.0, 2.5 , and $5 \mathrm{~g} \mathrm{~cm}^{-3}$ to evaluate the dependence of the model predictions on the assumed particle density. An iodine oxide density of $1.0 \mathrm{~g} \mathrm{~cm}^{-3}$ was reported by Jimenez et al. (2003) for 100 to $200 \mathrm{~nm}$ diameter particles. Jimenez et al. (2003) also determined that particles in this size range had fractal structures. Therefore, this density may or may not be appropriate for the smaller particle sizes in our experiments. A density of $2.5 \mathrm{~g} \mathrm{~cm}^{-3}$ was used to represent the bulk density for the $\mathrm{I}_{2} \mathrm{O}_{4}$ crystal reported by Fjelvag and Kjekshus (1994). This density represents an upper limit to the new particle density while iodine oxide particles with fractal structures would have lower densities. However, $\mathrm{I}_{2} \mathrm{O}_{5}$, a iodine oxide expected to be very similar in structure to $\mathrm{I}_{2} \mathrm{O}_{4}$, has a significantly higher bulk density, $5.08 \mathrm{~g} \mathrm{~cm}^{-3}$ (Selte and Kjekshus, 1970). 

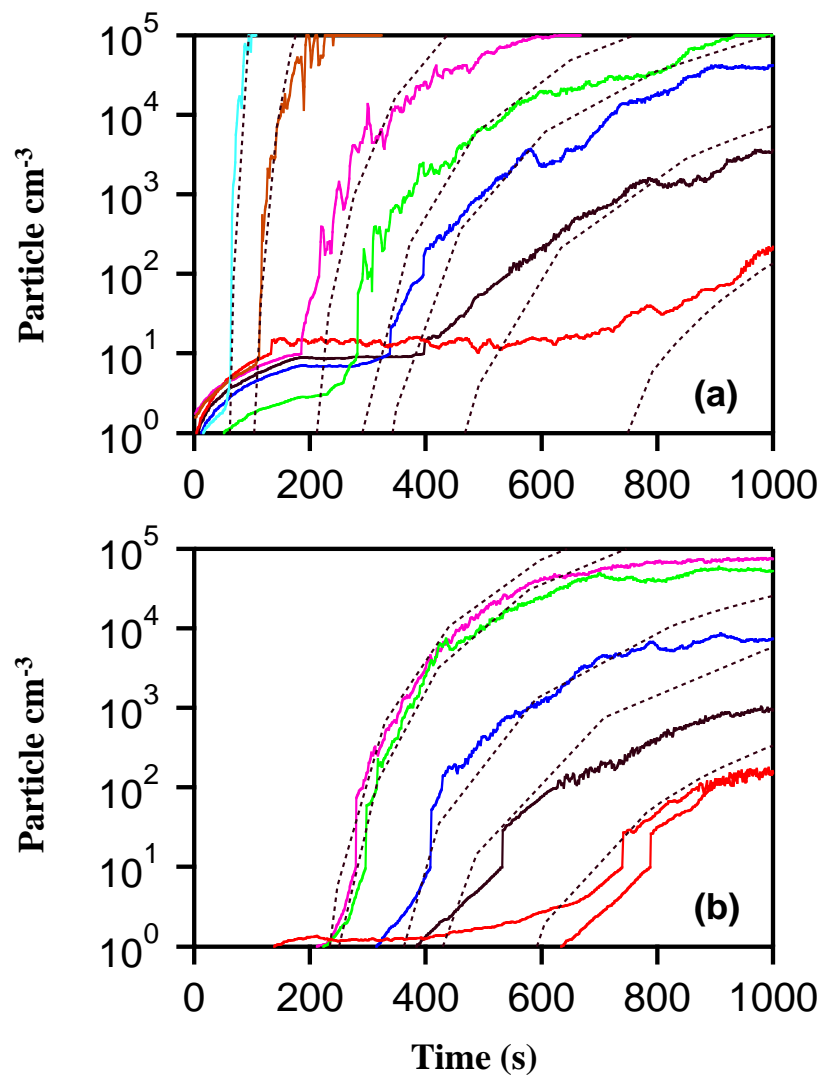

Fig. 7. Particle production dependence on the initial $\mathrm{CH}_{2} \mathrm{I}_{2}$ concentration measured using BLB365 lamp continuous photolysis. (a) initial $\mathrm{CH}_{2} \mathrm{I}_{2}$ concentrations of 0 (red), 15 (black), 29 (blue), 45 (green), 93 (purple), 531 (brown), and 1500 (light blue) ppt with $50 \mathrm{ppb} \mathrm{O}_{3}$. (b) initial $\mathrm{CH}_{2} \mathrm{I}_{2}$ concentrations were 0 (red, two measurements), 6.6 (black), 13.7 (blue), 26.1 (green), and 41.4 (purple) ppt with $500 \mathrm{ppb} \mathrm{O}_{3}$. The aerosol model simulations are shown as dashed lines (see text for details).

Therefore, model calculations using a density of $5.0 \mathrm{~g} \mathrm{~cm}^{-3}$ have also been included in this analysis.

The conclusions drawn from these model calculations are: (1) The optimized thermodynamic parameters were independent of the particle density, (2) A density of $5.0 \mathrm{~g} \mathrm{~cm}^{-3}$ does not reproduce the experimental data very well. These calculations fail to capture the correct induction time for particle detection (too late), the rate of rise in the particle concentration (too fast), and the particle concentration at the end of the observation time (too high). Using an uptake coefficient value less than 1.0 yielded even worse fits to the experimental data. (3) A density of $2.5 \mathrm{~g} \mathrm{~cm}^{-3}$ with an uptake coefficient of 1.0 reproduces the experimental data very well. These are the model parameters given in Table 3 and used for all the figures in this paper. (4) A density of $1.0 \mathrm{~g} \mathrm{~cm}^{-3}$ also reproduces the experimental data very well with an uptake coefficient value of $\sim 0.3$. This would be consistent with a fractal particle geometry for small particles, $<50 \mathrm{~nm}$ diameter, and a physically realistic uptake coefficient.
There are no direct studies of OIO uptake coefficients available in the literature. Jimenez et al. (2003) report an uptake coefficient of near unity based on their iodine oxide particle growth data analysis. Allan et al. (2001) have analyzed their OIO field measurement data using an OIO uptake coefficient of 0.02 on background aerosol in the marine boundary layer. While this value is significantly different than used in our data analysis it represents uptake on aerosol of significantly different composition than found in the laboratory studies. Direct measurement of OIO uptake coefficients on aerosol of various compositions would help to resolve this issue.

As shown in the experimental data figures presented so far, the aerosol model does a good job in reproducing the total particle $(>3 \mathrm{~nm})$ concentration profiles. As a further test, measurements using the n-DMA with $21.0 \mathrm{ppb} \mathrm{CF}_{3} \mathrm{I}$ and 30 and $300 \mathrm{ppb}_{3}$ and continuous photolysis (BL350 lamps) were performed. Representative experimental data for 3, 5, 8,10 , and $15 \mathrm{~nm}$ diameter particles are shown in Fig. 6a. The particle concentration profiles were recorded in separate measurements under identical initial conditions. The measured profiles were independent of the initial $\mathrm{O}_{3}$ concentration. The aerosol model calculations for these size particles are shown in Fig. 6b. The model results have been scaled to account for the n-DMA size dependent charging efficiency, as described in the operating manual, and its transfer function (Chen et al., 1998). The model profiles show good agreement with the experimental data.

\subsection{Summary of $\mathrm{CH}_{2} \mathrm{I}_{2}$ experiments}

Complications from background particle production, i.e. $\mathrm{CH}_{2} \mathrm{I}_{2} / \mathrm{O}_{3}$ mixture but no UV photolysis, in the $\mathrm{CH}_{2} \mathrm{I}_{2}$ experiments were encountered. As observed in the $\mathrm{CH}_{3} \mathrm{I}$ measurements, the background particle production was dependent on the room light intensity. At $\mathrm{CH}_{2} \mathrm{I}_{2}$ concentrations less than $500 \mathrm{ppt}$ the background particle production was not observed over the time scale of a typical experiment, $<1000 \mathrm{~s}$. Therefore, although there is an appreciable $\mathrm{I}_{2} \mathrm{im}$ purity it may not influence these nucleation experiments. A second complication was the general level of reproducibility in the particle production in the low $\mathrm{CH}_{2} \mathrm{I}_{2}$ concentration, $<200 \mathrm{ppt}$, experiments. The irreproducibility appeared to be dependent on the history of the reactor and are consistent with a residual $\mathrm{CH}_{2} \mathrm{I}_{2}$ concentration (of the order $10 \mathrm{ppt}$ ) in the reactor that was not efficiently flushed out of the bag between experiments. It should be pointed out that this was not a problem in the $\mathrm{CF}_{3} \mathrm{I}$ experiments indicating that secondary reaction products or particle formation in the reactor was not the source of the problem. A residual $\mathrm{CH}_{2} \mathrm{I}_{2}$ concentration has the most dramatic effect on the particle production in the low concentration experiments while being insignificant in the high concentration experiments, $>200 \mathrm{ppt}$.

$\mathrm{CH}_{2} \mathrm{I}_{2}$ experiments were performed in a similar way as described above for $\mathrm{CF}_{3} \mathrm{I}$. Figure 7 shows the particle 
production dependence on the initial $\mathrm{CH}_{2} \mathrm{I}_{2}$ concentration with ozone concentrations of 50 and $500 \mathrm{ppb}$. The background particle production in the absence of added $\mathrm{CH}_{2} \mathrm{I}_{2}$ is also shown. The background particle production was weakly dependent on the ozone concentration and is consistent with Reaction (18) leading to OIO formation. A background concentration of $\sim 15$ to $30 \mathrm{ppt} \mathrm{CH}_{2} \mathrm{I}_{2}$ was used to bring the model and experimental results into agreement. Also, the experimental data is most consistent with the model assumption of prompt iodine release from the $\mathrm{CH}_{2} \mathrm{IOO}$ radical. Similar results were observed in experiments performed using the BL350 photolysis lamps.

Photolysis pulse experiments with $185 \mathrm{ppt} \mathrm{CH}_{2} \mathrm{I}_{2}, 50 \mathrm{ppb}$ $\mathrm{O}_{3}$ and photolysis times of 30,60, 90, and $120 \mathrm{~s}$ are shown in Fig. 8. The photolysis durations correspond to I atom production of $6.8,13.4,19.7$, and 25.8 ppt. The shortest photolysis duration, $30 \mathrm{~s}$, did not produce a measurable particle production over the first $600 \mathrm{~s}$ while the aerosol model predicts a small yield. The particle production observed with the longer photolysis durations show good agreement with the model simulations and a strong non-linear dependence on the reactive iodine concentration as in the $\mathrm{CF}_{3} \mathrm{I}$ experiments. In addition to these measurements, a single measurement at twice the initial $\mathrm{CH}_{2} \mathrm{I}_{2}$ concentration and 60 s photolysis showed reasonable agreement with the $120 \mathrm{~s}$ data indicating a self-consistency of the particle production with the total iodine atom production. In general, the $\mathrm{CH}_{2} \mathrm{I}_{2}$ experimental data is self-consistent with the $\mathrm{CF}_{3} \mathrm{I}$ data provided a small $\mathrm{CH}_{2} \mathrm{I}_{2}$ background concentration is included in the model calculations.

\subsection{Particle production temperature dependence}

The experimental data presented so far was recorded at $298 \mathrm{~K}$. The chemical reaction mechanism (and therefore the iodine radical concentrations) is relatively insensitive to small changes in temperature. However, cluster formation and particle nucleation are expected to demonstrate a strong temperature dependence mostly due to the strong temperature dependence of cluster evaporation. The temperature dependence could play an important role in particle formation in the colder regions of the atmosphere. Therefore, we have evaluated the particle production temperature dependence in experiments performed at two different initial $\mathrm{CF}_{3} \mathrm{I}$ concentrations (21.0 and $5 \mathrm{ppb}$ ) at 296,308 , and $318 \mathrm{~K}$. The experimental data is summarized in Fig. 9. At $21.0 \mathrm{ppb} \mathrm{CF}_{3} \mathrm{I}, \tau$ did not change with temperature within the precision of the measurement. However, the rate of increase in the particle concentration decreased with increasing temperature. At $5.5 \mathrm{ppb}$ $\mathrm{CF}_{3} \mathrm{I}, \tau$ was observed to increase with increasing temperature.

Aerosol model simulations using the parameters determined from the analysis of the $\mathrm{CF}_{3} \mathrm{I}$ room temperature data are also shown in Fig. 9. In general, the model simulations qualitatively reproduce the effects of temperature but do not

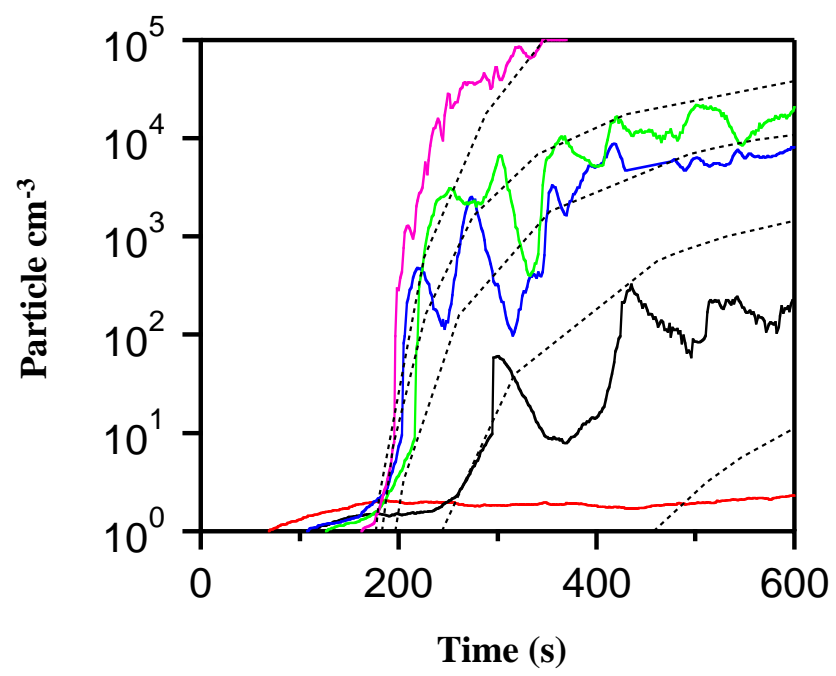

Fig. 8. Particle production following $30 \mathrm{~s}$ (red), $60 \mathrm{~s}$ (black), $90 \mathrm{~s}$ (blue), and $120 \mathrm{~s}$ (green) photolysis pulses (BLB365 lamps) with $185 \mathrm{ppt} \mathrm{CH}_{2} \mathrm{I}_{2}$ and $50 \mathrm{ppb} \mathrm{O}$. The particle production measured under these concentrations with continuous photolysis is shown for comparison (purple). The photolysis pulses correspond to I atom production concentrations of $6.8,13.4,19.7$, and $25.8 \mathrm{ppt}$, respectively. The aerosol model simulations are given as the dashed lines (see text for details).

capture the dependence on temperature quantitatively. These measurements show that temperature will have a significant influence on the efficiency of particle production in the iodine oxide system. Further work is needed to refine the potentially important effect of temperature on particle production.

\subsection{Comparison with previous studies}

Aerosol formation has been observed in iodine/ozone reaction systems and reported in numerous studies (Cox and Coker, 1983; Harwood et al., 1997; Hoffmann et al., 2001; Jimenez et al., 2003). The more recent studies of Hoffmann et al. (2001) and Jimenez et al. (2003) provide the most quantitative data for comparison with the present work and are considered in more detail here. In both studies, UV photolysis of $\mathrm{CH}_{2} \mathrm{I}_{2}$ in the presence of excess $\mathrm{O}_{3}$ was used to initiate gas phase iodine chemistry (see reaction mechanism above and Table 2 in Jimenez et al. (2003) for details) leading to new particle formation. Hoffmann et al. used relatively high initial concentrations of $\mathrm{CH}_{2} \mathrm{I}_{2}$ (4 and $17 \mathrm{ppb}$ ) while Jimenez et al. made measurements at lower, more atmospherically relevant, $\mathrm{CH}_{2} \mathrm{I}_{2}$ concentrations (down to $15 \mathrm{ppt}$ ). Based on their mass spectrometric aerosol composition measurements and previously published studies of iodine oxides, Hoffmann et al. proposed that OIO was responsible for the observed particle formation. However, particle formation under these highly super-saturated conditions (i.e. high radical concentrations) is insensitive to the thermodynamics of the initial nucleation steps (i.e. nucleation is 

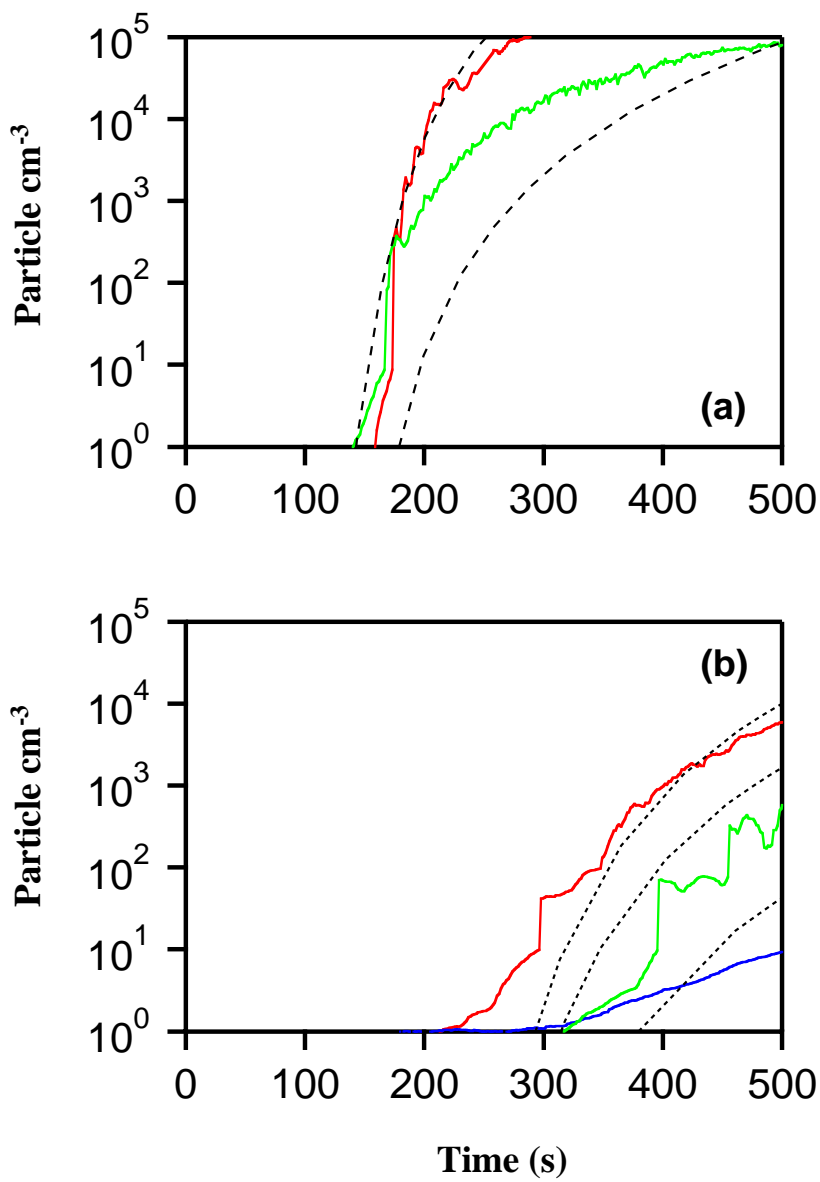

Fig. 9. Particle production temperature dependence measurements. Experimental data (a) measured with $\left[\mathrm{CF}_{3} \mathrm{I}\right]=21.0 \mathrm{ppb}$ at $296 \mathrm{~K}$ (red) and $318 \mathrm{~K}$ (green) (b) with $\left[\mathrm{CF}_{3} \mathrm{I}\right]=5.5 \mathrm{ppb}$ at $296 \mathrm{~K}$ (red), $308 \mathrm{~K}$ (green), and $318 \mathrm{~K}$ (blue). The aerosol model simulations are shown as the short dashed lines (see text for details).

near the collision limit). Therefore, a quantitative comparison using our aerosol model with the Hoffmann et al. data was not pursued.

Jimenez et al. (2003) have reported data for iodine oxide aerosol formation under a wider range of experimental conditions (initial $\mathrm{CH}_{2} \mathrm{I}_{2}$, relative humidity, and $\mathrm{CH}_{2} \mathrm{I}_{2}$ photolysis rate coefficients) than used in the Hoffmann et al. study. Their measurements made with lower $\mathrm{CH}_{2} \mathrm{I}_{2}$ concentrations, $<5 \mathrm{ppb}$, provide data which is more sensitive to the initial iodine oxide nucleation steps and therefore are appropriate for comparison within the framework of our aerosol model. The experiments of Jimenez et al. also provided quantitative information for the physical properties of the iodine aerosol (density, hygroscopicity) and composition that were incorporated into the development of our aerosol model.

A comparison of aerosol model simulations (or our experimental data) with the data reported by Jimenez et al. has caveats. In principle, the experiments are similar in design and a direct comparison of results could be made. However, there are differences in the experimental particle sampling methods used that impede a direct comparison. Jimenez et al. extended the concentration range of their particle counter by diluting the aerosol sampling flow by a factor of 1000 , yielding an upper limit of $10^{8}$ particle $\mathrm{cm}^{-3}$ for the UCPC. The dilution was necessary in their experiments to enable monitoring of the particle growth following the initial nucleation burst. Our measurements did not employ a sample dilution and were therefore limited to particle concentrations less than $10^{5}$ particle $\mathrm{cm}^{-3}$. Diluting the sample has several effects that result in decreased particle detection efficiency. The decreased efficiency is greatest for small particles and was estimated by Jimenez et al. to be $\sim 0.17 \%, 8.4 \%, 30 \%$, and $88 \%$ for $3,6,10$, and $50 \mathrm{~nm}$ diameter particles, respectively. Uncertainties in the detection efficiency are a primary limitation in the comparison of the Jimenez et al. experimental data and our aerosol model calculations.

We have used the values of $\tau$ and the peak particle concentration reported by Jimenez et al. (2003) to compare with our aerosol model simulations. We found the modeled values of $\tau$ to be systematically greater, $\sim 10 \%$, than the reported values. Direct experimental measurements of the particle detection efficiency in the Jimenez et al. measurements as a function of particle size would be necessary to refine this analysis. Jimenez et al. show the particle concentration pro-

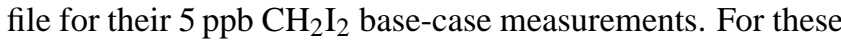
conditions the modeled rate of rise in the particle concentration was more rapid than observed. This rate is, however, sensitive to the photolysis rate coefficient and a small decrease, $\sim 25 \%$, in this value is sufficient to reproduce the experimentally observed rate of rise in the particle concentration. Finally, the peak particle concentrations calculated in our aerosol model are systematically higher, approximately a factor of four, than the reported values. Considering all the assumptions made in this analysis, we consider this to be reasonable agreement.

We should also point out that the model evaluation of the Jimenez et al. $15 \mathrm{ppt} \mathrm{CH}_{2} \mathrm{I}_{2}$ data is extremely sensitive to the initial concentration. An uncertainty in the initial $\mathrm{CH}_{2} \mathrm{I}_{2}$ concentration of a few ppt has a dramatic affect on both $\tau$ and the final particle concentration. The experimental data was reproduced in our model using an initial $\mathrm{CH}_{2} \mathrm{I}_{2}$ concentration of $18 \mathrm{ppt}$. In conclusion, this semi-quantitative model analysis of the Jimenez et al. data demonstrates a reasonable level of consistency with the results of our nucleation experiments.

\section{Atmospheric implications}

In this section, we address the significance of the iodine oxide aerosol production on both local and regional scale in the marine boundary layer (MBL). We have used the recently reported field measurements of IO, OIO, and ultra-fine aerosol and the aerosol model parameters determined in this study in a box-model to evaluate the efficiency of the iodine oxide 
aerosol formation in the MBL. We present results from three model calculations in which OIO is assumed to be the homogeneous nucleating species with the mechanism outlined in this paper. Two calculations utilize the field observations of $\mathrm{OIO}$ and IO to define their concentrations. The final calculation evaluates the possible influence of localized "hot" spots in the iodine oxide concentrations on the aerosol production. In this calculation, we have extended the calculations beyond the range of the field measurements to evaluate under what atmospheric concentrations of IO and OIO aerosol formation can be expected.

In the first atmospheric box-model calculation we address the question: What concentration of OIO is required to yield the particle concentrations observed at Mace Head station? Field measurements of OIO are very limited. In fact, Allan et al. (2001) have reported the only field measurement of OIO off the coast of Cape Grim, Tasmania. The OIO concentration was below the detection limit, $\sim 0.5 \mathrm{ppt}$, during daylight and increased to $\sim 3 \mathrm{ppt}$ for several hours just after sunset. Measurements of aerosol production were not reported as part of this study. Measurements of the OIO concentration at the Mace Head station during the period of the PARFORCE have not been reported in the literature. In our model, the particle concentration as a function of time was calculated as a function of a steady-state OIO concentration. The model was run for two hours to cover the time frame for aerosol formation observed during the PARFORCE campaign at Mace Head station. Calculations were performed using the optimized model parameters (determined above) with OIO steady state concentrations between 0.5 and $100 \mathrm{ppt}$ at temperatures of $270,280,290$, and $300 \mathrm{~K}$. The model results are summarized in Fig. 10.

It is evident from Fig. 10 that OIO steady-state concentrations similar to the value reported by Allan et al. (2001), $\sim 0.5 \mathrm{ppt}$, are not sufficient to yield the particle concentrations observed at Mace Head station. In fact, an OIO concentration of $0.5 \mathrm{ppt}$ would not yield measurable particle formation within $2 \mathrm{~h}$. However, a steady-state concentration of $10 \mathrm{ppt}$ would yield $10^{6}$ particle $\mathrm{cm}^{-3}$ within 10 to $20 \mathrm{~min}$ and be more consistent with the particle production observed at Mace Head Atmospheric Research station. It may be possible that high concentrations of OIO, $>10 \mathrm{ppt}$, are present in localized "hot" spots along the coast region. In this case the coast region would consist of an inhomogeneous source of OIO. Following dilution of the aerosol produced in the "hot" spot, this could still account for the observed particle concentrations. More extensive and localized field measurements of OIO in the MBL and its correlation with aerosol production would be invaluable in evaluating this hypothesis. Although the particle production dependence on temperature was not accurately defined in the present study, the atmospheric box-model calculations shown in Fig. 10 demonstrate its importance. For example, a factor of 1000 increase in particle yield is calculated for a decrease in temperature from $300 \mathrm{~K}$ to $270 \mathrm{~K}$.

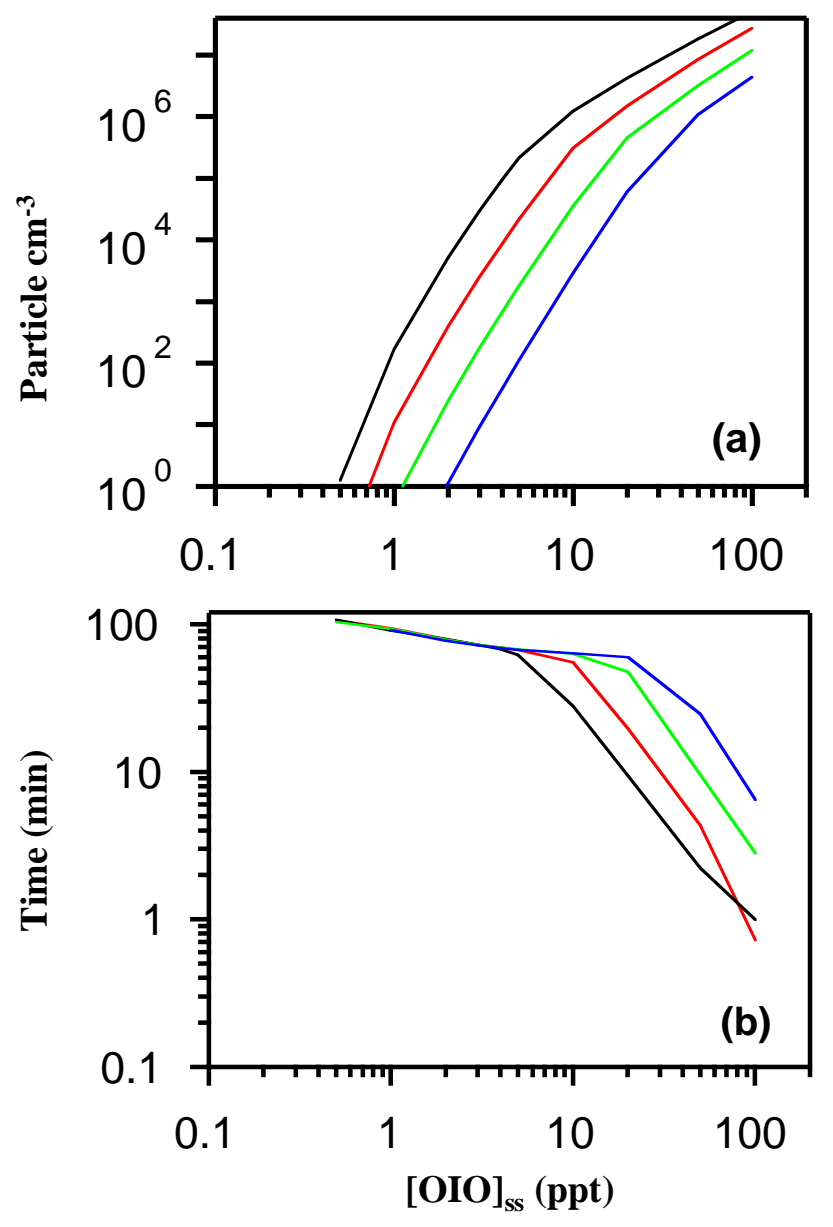

Fig. 10. Aerosol production $(d>3 \mathrm{~nm})$ calculated assuming a steady state concentration of OIO at $270 \mathrm{~K}$ (black), $280 \mathrm{~K}$ (red), $290 \mathrm{~K}$ (green), and $300 \mathrm{~K}$ (blue). (a) peak particle concentration reached in the first two hours (b) time required to reach half the peak particle concentration shown in frame (a).

The flux of iodine containing compounds in the open ocean is expected to differ significantly from that found in the coastal regions. In the coastal regions, emission of $\mathrm{CH}_{2} \mathrm{I}_{2}$ from macroalgae under stress (i.e. low tide) is expected to be much larger than found in the open ocean. The lone reported field measurement of OIO, $<0.5 \mathrm{ppt}$, at Cape Grim, Tasmania (Allan et al., 2001) includes coastal influences but may represent an upper limit for the OIO concentration in the open ocean. Our aerosol model calculations would lead us to conclude that OIO homogeneous nucleation in the open ocean would not be a significant source of new particles in the MBL at these concentrations. A recent modeling study by O'Dowd et al. (2002) however has shown that iodine oxides could contribute to the growth of small, $\sim 1 \mathrm{~nm}$ diameter, sulfuric acid particles into detectable sizes, $>3 \mathrm{~nm}$ diameter. Further open ocean modeling studies using the iodine oxide nucleation parameters determined in this study and direct measurements of the OIO concentration in the open ocean could aid the refinement of this analysis. 

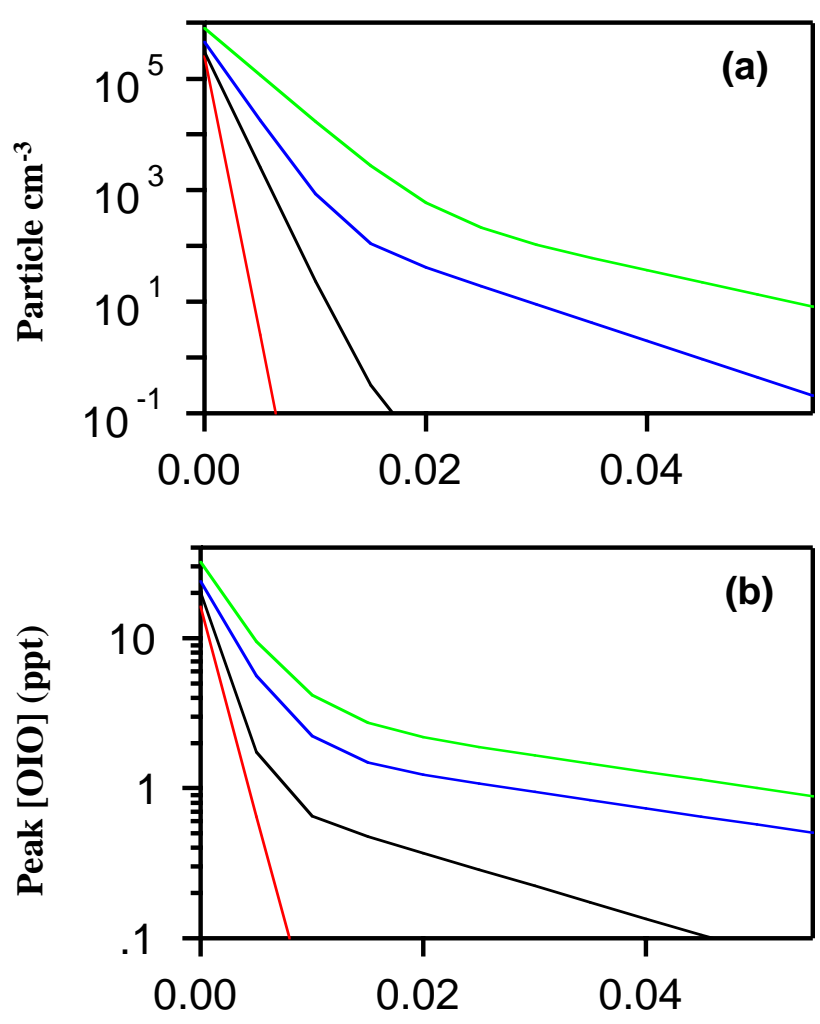

OIO Loss Rate Coefficient $\left(\mathrm{s}^{-1}\right)$

Fig. 11. Summary of atmospheric box-model calculations with $T=287 \mathrm{~K}$ and a diurnal IO profile with peak concentrations of 0.5 (red), 1.0 (black), 3.0 (blue), and 5.0(green) ppt and a variable OIO first order loss rate coefficient (see text for details).

In the second model calculation, we address the question: Using the field mesasured IO radical concentrations, what are the expected iodine oxide particle concentrations? In this approach we utilize the extensive field observations of the IO radical. There are a number of high quality field measurements of IO in the MBL made using long path absorption techniques (Alicke et al., 1999; Allan et al., 2000, 2001; Frieb et al., 2001). These measurements provide an important guide to iodine oxide aerosol formation because IO is the precursor for OIO formation either through Reaction (3), IO + IO, or via $\mathrm{IO}+\mathrm{BrO}$ (Rowley et al., 2001). The IO + BrO reaction is expected to be a minor source of OIO in the MBL due to the low $\mathrm{BrO}$ concentrations. Under certain conditions common to the open ocean, Reaction (18), $\mathrm{IO}+\mathrm{O}_{3}$, could be the major source of OIO.

The measured IO concentration shows a strong correlation with solar flux and reaches values up to $\sim 6 \mathrm{ppt}$ at mid-day and below the detection limit $(0.5 \mathrm{ppt})$ at night. The peak IO concentrations measured in three separate locations (Mace Head, Ireland; Tenerife, Canary Islands; and Cape Grim, Tasmania) by Allan et al. (2001) were very similar, $\sim 2$ ppt. Alicke et al. (1999) report slightly higher values in their mea- surements at Mace Head, Ireland. The differences in the two Mace Head, Ireland studies may reflect differences in the air masses sampled. For example, much of the optical path length $(8.4 \mathrm{~km})$ in the Allan et al. study (EASE 97$)$ was over the open sea between Croaghnakeela Island and the Mace Head station. Therefore fluctuations in the IO concentrations in the coastal region may have been poorly sampled.

Using known gas phase chemistry of the IO radical, the OIO concentration and the resulting particle production was modeled. In this calculation the atmospheric loss processes for OIO such as reaction, deposition, and photolysis that are currently not very well characterized need to be included. Reaction of $\mathrm{OIO}$ with $\mathrm{Cl}, \mathrm{OH}$ and $\mathrm{NO}$ are the most likely reactive losses for OIO in the MBL. Rate coefficients for these reactions on the order of $10^{-12} \mathrm{~cm}^{3}$ molecule $e^{-1} \mathrm{~s}^{-1}$ for $\mathrm{OH}$ and $\mathrm{NO}$ and $10^{-10} \mathrm{~cm}^{3}$ molecule ${ }^{-1} \mathrm{~s}^{-1}$ for $\mathrm{Cl}$ reactions are reasonable estimates. Only the $\mathrm{NO}$ concentration is expected to be high enough in the MBL, 10 to $20 \mathrm{ppt}$, to possibly have an impact on iodine oxide aerosol formation. Uptake of OIO on background aerosol would also limit the OIO concentration. The uptake loss rate will depend on the background aerosol surface area and the efficiency of OIO uptake. In their field measurements, Allan et al. (2001) attributed loss of OIO after sunset to uptake on background aerosol with a lifetime of several hours. Photodissociation of OIO in its visible absorption band

$$
\begin{aligned}
\mathrm{OIO}+\mathrm{h} v & \rightarrow \mathrm{O}+\mathrm{IO} \\
& \rightarrow \mathrm{I}+\mathrm{O}_{2}
\end{aligned}
$$

is potentially the most significant loss process for OIO in the MBL. OIO photolysis lifetimes on the order of seconds are possible provided that absorption over the entire visible absorption band leads to photodissociation. The threshold for Reaction (19a) has been calculated to be at $\sim 410 \mathrm{~nm}$ (Misra and Marshall, 1998) while Reaction (19b) is possible over the entire absorption band. Either channel would directly affect the efficiency of particle production through the loss of OIO.

The box-model was run over a $12 \mathrm{~h}$ period using a diurnal cycle for the IO concentration as reported by Allan et al. (2000). Calculations were performed with peak IO concentration values of $0.5,1.0,3.0$, and $5.0 \mathrm{ppt}$ to cover the range observed in the field measurements. The OIO first order loss rate coefficient, $k_{19}$, was varied over the range 0 to $0.05 \mathrm{~s}^{-1}$ in these calculations. The peak particle concentration and maximum $\mathrm{OIO}$ concentration, $[\mathrm{OIO}]_{\max }$, reached during the $12 \mathrm{~h}$ period for these conditions are summarized in Fig. 11.

The first conclusion drawn from this calculation is that significant aerosol production occurs within the first few hours for each of the IO concentrations used provided $k_{19}<0.005 \mathrm{~s}^{-1}$. The OIO concentration reaches values of 10 's of ppt near the end of the calculation for $k_{19}<0.005 \mathrm{~s}^{-1}$. Second, particle production and the $[\mathrm{OIO}]_{\max }$ values have a 
very strong dependence on the value of $k_{19}$, i.e. they rapidly decrease with increasing $k_{19}$. An accurate value of $k_{19}$ is crucial to the evaluation of this aerosol production mechanism. These calculations also demonstrate that OIO loss processes such as reaction and uptake that are on the order of $10^{-4} \mathrm{~s}^{-1}$ may only be minor relative to the photolysis loss.

In the third model calculation we address the question: What IO concentration would be needed to achieve the observed aerosol production at Mace Head station? As demonstrated in the calculations presented above, the OIO steady state concentration needs to be in the $10 \mathrm{ppt}$ range to yield the observed particle concentrations. To a first approximation, $[\mathrm{OIO}]_{\mathrm{ss}}=k_{3}[\mathrm{IO}]_{\mathrm{ss}}^{2} / k_{19}$ which implies, depending on the value of $k_{19}$, that [IO $]_{\mathrm{ss}}$ would need to be in the range of tens to hundreds ppt. The box-model calculation results for a range of [IO $]_{\mathrm{ss}}$ values from 50 to $200 \mathrm{ppt}$ and $k_{19}$ values from 0.25 to $2 \mathrm{~s}^{-1}$ are shown in Fig. 12. The value of $k_{19}=2 \mathrm{~s}^{-1}$ represents a reasonable upper limit for the photolysis rate coefficient of OIO in the MBL. This calculation shows that the observed particle concentrations at Mace Head (and their rapid formation) can be reproduced with $[\mathrm{IO}]_{\mathrm{ss}}$ of 50 to $100 \mathrm{ppt}$. These high IO concentrations are in conflict with the published field measurements of IO (derived from long path absorption measurements) but would be consistent with the hypothesis of localized "hot" spots of high iodine emission.

\section{Conclusions}

In this work, iodine oxide nucleation was examined using laboratory measurements of new particle production and analysis with a coupled chemical-aerosol model. It is observed that new particle formation in this system is efficient. Model parameters that describe the single component homogeneous nucleation of OIO are determined.

Atmospheric box-model calculations show that the IO and OIO concentrations reported in the recent field measurements in the marine boundary layer (Allan et al., 2000, 2001) are not sufficient to account for significant aerosol production either in the coastal or open ocean marine boundary layer. Model calculations demonstrate that inhomogeneous sources of iodine oxides, i.e. "hot" spots with elevated iodine precursor (i.e. $\mathrm{CH}_{2} \mathrm{I}_{2}$ ) emissions, could possibly account for the observed large aerosol production in the coastal region at Mace Head station. This hypothesis awaits confirmation by future field studies.

Acknowledgements. We thank P. Marshall, T. Cox, J. Jimenez, Ch. Brock, and T. Baynard for helpful discussions during the course of this work. We thank B. Kuster for the GC analysis of the synthetic air cylinder. We acknowledge funding from NOAA's Global and Climate Change Program. JC thanks the Max-Planck-society for an Otto-Hahn research fellowship.
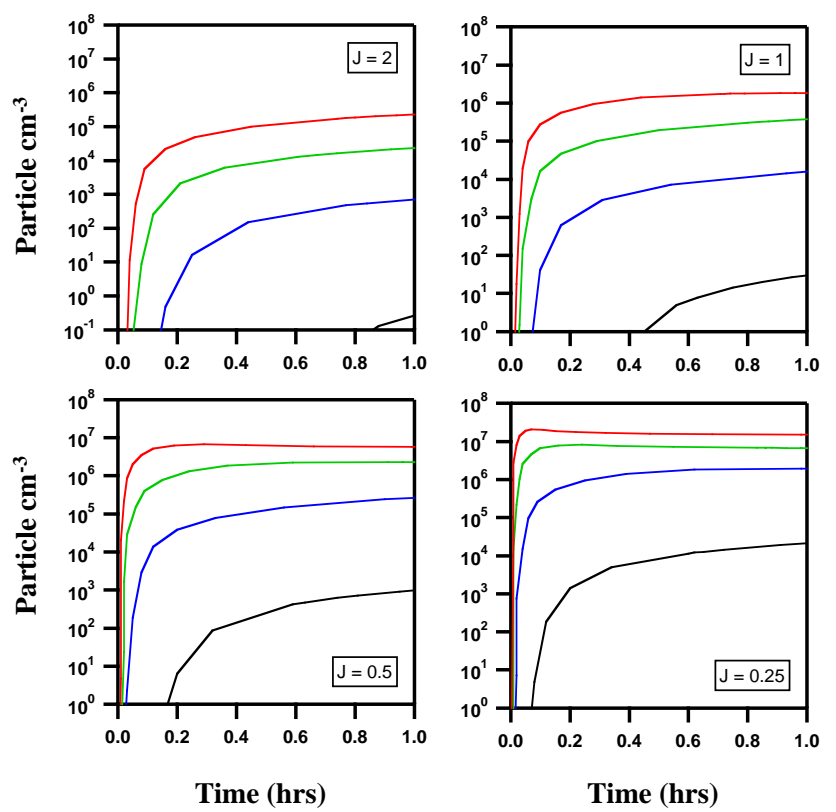

Fig. 12. Aerosol model calculations of particle production $(>3 \mathrm{~nm}$ dia., $T=287 \mathrm{~K}$ ) with IO steady state concentrations of $50 \mathrm{ppt}$ (black), $100 \mathrm{ppt}$ (blue), $150 \mathrm{ppt}$ (green), and $200 \mathrm{ppt}$ (red). Calculations were performed with the thermodynamic parameters determined in this work for OIO photolysis rate coefficients of 2, 1, 0.5, and $0.25 \mathrm{~s}^{-1}$ (see text for details).

\section{References}

Allan, B. J., McFiggans, G., Plane, J. M. C., and Coe, H.: Observations of iodine monoxide in the remote marine boundary layer, $\mathrm{J}$. Geophys. Res., 105, 14 363-14369, 2000.

Allan, B. J., Plane, J. M. C., and McFiggans, G.: Observations of OIO in the remote marine boundary layer, Geophys. Res. Lett., 28, 1945-1948, 2001.

Alicke, B., Hebestreit, K., Stutz, J., and Platt, U.: Iodine oxide in the marine boundary layer, Nature, 397, 572-573, 1999.

Ashworth, S. H., Allan, B. J., and Plane, J. M. C.: High resolution spectroscopy of the OIO radical: Implications for the ozone-depleting potential of iodine, Geophys. Res. Lett., 29, doi: 10.1029/2001GL013851, 2002.

Atkinson, R., Baulch, D. L., Cox, R. A., Crowley, J. N., Hampson Jr., R. F., Kerr, J. A., Rossi, M. J., and Troe, J.: IUPAC, Summary of evaluated kinetic and photochemical data for atmospheric chemistry, http://www.iupac-kinetic.ch.cam.ac.uk/, 2003.

Bloss, W. J., Rowley, D. M., Cox, R. A., and Jones, R. L.: Kinetics and products of the IO self-reaction, J. Phys. Chem. A, 105, 7840-7854, doi: 10.1021/jp012429y, 2001.

Carpenter, L. J., Hebestreit, K., Platt, U., and Liss, P. S.: Coastal zone production of IO precursors: a 2-dimensional study, Atmos. Chem. Phys., 1, 9-18, 2001.

Chen, D.-R., Pui, D. Y. H., Hummes, D., Fissan, H., Quant, F. R., and Sem, G. J.: Design and evaluation of a nanometer aerosol differential mobility analyzer (nano-DMA), J. Aerosol Science, 29, 497-509, 1998.

Cox, R. A. and Coker, G. B.: Absorption cross section and kinetics 
of IO in the photolysis of $\mathrm{CH}_{3} \mathrm{I}$ in the presence of ozone, J. Phys. Chem., 87, 4478-4484, 1983.

Fjellvag, $\mathrm{H}$. and Kjekshus, A.: The crystal structure of $\mathrm{I}_{2} \mathrm{O}_{4}$ and its relations to other iodine-oxygen-containing compounds, Acta Chemica Scandinavica, 48, 815-822, 1994.

Frieb, U., Wagner, T., Pundt, I., Pfeilsticker, K., and Platt, U.: Spectroscopic measurements of tropospheric iodine oxide at Neumayer Station, Antarctica, Geophys. Res. Lett., 28, 1941-1944, 2001.

Harwood, M. H., Burkholder, J. B., Hunter, M., Fox, R. W., and Ravishankara, A. R.: Absorption cross sections and self-reaction kinetics of the IO radical, J. Phys. Chem. A, 101, 853-863, 1997.

Hoffmann, T., O'Dowd, C. D., and Seinfeld, J. H.: Iodine oxide homogeneous nucleation: An explanation for coastal new particle production, Geophys. Res. Lett., 28, 1949-1952, 2001.

Ingham, T., Cameron, M., and Crowley, J. N.: Photodissociation of IO $(355 \mathrm{~nm})$ and OIO $(532 \mathrm{~nm})$ : Quantum yields for $\mathrm{O}\left({ }^{3} \mathrm{P}\right)$ and $\mathrm{I}\left({ }^{2} \mathrm{P}_{J}\right)$ production, J. Phys. Chem. A., 104, 8001-8010, 2000.

Jimenez, J. L., Bahreini, R., Cocker III, D. R., Zhuang, H., Varutbangkul, V., Flagan, R. C., and Seinfeld, J. H., O’Dowd, C. D., and Hoffmann, T.: New particle formation from photooxidation of diiodomethane $\left(\mathrm{CH}_{2} \mathrm{I}_{2}\right)$, J. Geophys. Res., 108, D10, 4318, doi: 10.1029/2002JD002452, 2003.

Kavouras, I. G., Mihalopoulos, N., and Stephanou, E. G.: Formation of atmospheric particles from organic acids produced by forests, Nature, 395, 683-686, 1998.

Kavouras, I. G., Mihalopoulos, N., and Stephanou, E. G.: Formation and gas/particle partitioning of monoterpenes photooxidation products over forests, Geophys. Res. Lett., 26, 55-58, 1999.

Leaitch, W. R., Bottenheim, J. W., Biesenthal, T. A., Li, S. M., Liu, S. K., Asalien, K., Dryfhout-Clark, H., Hopper, F., and Brechtel, F.: A case study of gas-to-particle conversion in an eastern Canadian forest, J. Geophys. Res., 104, 8095-8111, 1999.

Marti, J. J., Weber, R. J., McMurry, P. H., Eisele, F. L., Tanner, D. J., and Jefferson, A.: New particle formation at a remote continental site: Assessing the contribution of $\mathrm{SO}_{2}$ and organic precursors, J. Geophys. Res., 102, 6331-6339, 1997.

Misra, A. and Marshall, P.: Computational investigations of iodine oxides, J. Phys. Chem. A, 102, 9056-9060, 1998.

O’Dowd, C. D., Hämeri, K, Mäkelä, J. M. et al.: A dedicated study of new particle formation and fate in the coastal environment (PARFORCE): Overview of objectives and achievements, J. Geophys. Res. 107, D19, 8108, doi:10.1029/2001JD000555, 2002.
O’Dowd, C. D., Jimenez, J. L., Bahreini, R., Flagan, R. C., Seinfeld, J. H., Kulmala, M., Pirjola, L., and Hoffmann, T.: Particle formation in the marine atmosphere controlled by biogenic iodine emissions, Nature, 417, 632-636, 2002.

Press, W. H., Teukolsky, S. A., Wetterling, W. T., and Flannery, B. T.: Numerical Recipes in Fortran 77: the Art of Scientific Computing, Cambridge University Press, Cambridge 1992.

Raes, F. and Janssens, A.: Ion-induced aerosol formation in a $\mathrm{H}_{2} \mathrm{O}-\mathrm{H}_{2} \mathrm{SO}_{4}$ system - I. Extension of the classical theory and search for experimental evidence, J. Aerosol Sci. 16, 217-227, 1985.

Raes, F. and Janssens, A.: Ion-induced aerosol formation in a $\mathrm{H}_{2} \mathrm{O}-\mathrm{H}_{2} \mathrm{SO}_{4}$ system - II. Numerical calculations and conclusions, J. Aerosol Sci. 17, 715-722, 1986.

Roehl, C. M., Burkholder, J. B., Moortgat, G. K., Ravishankara, A. R., and Crutzen, P. J.: Temperature dependence of UV absorption cross sections and atmospheric implications of several alkyl iodides, J. Geophys. Res. 102, D11, 12 819-12 829, 1997.

Rowley, D. M., Bloss, W. J., Cox, R. A., and Jones, R. L.: Kinetics and products of the $\mathrm{IO}+\mathrm{BrO}$ reaction, J. Phys. Chem. A, 105, 7855-7864, doi: 10.1021/jp004494y, 2001.

Sander, S. P., Finlayson-Pitts, B. J., Friedl, R. R., Golden, D. M., Huie, R. E., Kolb, C. E., Kurylo, Molina, M. J., Moortgat, G. K., Orkin, V. L., and Ravishankara, A. R.: Chemical kinetics and photochemical data for use in atmospheric studies, Evaluation 14, JPL publ. 02-25, http://jpldataeval.jpl.nasa.gov/, 2002.

Seinfeld, J. H. and Pandis, S. N.: Atmospheric Chemistry and Physics, John Wiley \& Sons, New York 1998.

Selte, K. and Kjekshus, A.: Iodine oxides: part III, The crystal structure of $\mathrm{I}_{2} \mathrm{O}_{5}$, Acta Chem. Scandinavica, 24, 1912-1924, 1970.

Solomon, S., Burkholder, J. B., Ravishankara, A. R., and Garcia, R. R.: Ozone depletion and global warming potentials of $\mathrm{CF}_{3} \mathrm{I}$, J. Geophys. Res., 99, D10), 20 929-20 935, 1994.

Turnipseed, A. A., Gilles, M. K., Burkholder, J. B., and Ravishankara, A. R.: LIF detection of IO and the rate coefficients for $\mathrm{I}+\mathrm{O}_{3}$ and $\mathrm{IO}+\mathrm{NO}$ reactions, Chem. Phys. Lett., 242, 427-434, 1995. 